\title{
Cancer and the kidney: dangereoux liasons or price paid for the progress in medicine?
}

\author{
Jolanta Małyszko ${ }^{1}$, Leszek Kozlowski², Klaudia Kozłowska ${ }^{1}$, Maciej Małyszko ${ }^{1}$ and \\ Jacek Małyszko ${ }^{3}$ \\ ${ }^{1}$ Second Department of Nephrology and Hypertension with Dialysis Unit, Medical University of Bialystok, Bialystok, Poland \\ ${ }^{2}$ Department of Oncological Surgery, Ministry of Interior Affairs, Bialystok, Poland \\ ${ }^{3}$ First Department of Nephrology and Transplantology with Dialysis Unit, Medical University of Bialystok, Bialystok, Poland \\ Correspondence to: Jolanta Małyszko, email: jolmal@poczta.onet.pl \\ Keywords: chronic kidney disease, malignancy, acute kidney injury, chemotherapy, kidney function \\ Received: February 17, $2017 \quad$ Accepted: April 23, $2017 \quad$ Published: May 23, 2017 \\ Copyright: Małyszko et al. This is an open-access article distributed under the terms of the Creative Commons Attribution License \\ 3.0 (CC BY 3.0), which permits unrestricted use, distribution, and reproduction in any medium, provided the original author and \\ source are credited.
}

\section{ABSTRACT}

A long time ago, the links between renal disease and malignancy were observed, however, quite recently, their importance was recognized and 'new' subspecialty in nephrology, namely 'onconephrology' was established. In the XXI century, patients with malignancy make up the most growing number of the subjects seen for nephrology consult and/or critical care nephrology services. A plethora of renal problems may be found in patients with malignancy. They may influence not only their short-term outcomes but also the adequate therapy of the underlying oncological problem. Thus, all these kidney-related issues pose an important challenge for both specialities: oncology and nephrology. In the review a spectrum of acute and chronic renal injury caused by the malignancy is presented as well as the associations between renal disease and cancer. Assessment of kidney function and its importance in patients with malignancy is also discussed as medical oncologists should check the appropriate dose of chemotherapeutic drugs in relation to the actual renal function before prescribing them to the patients. Moreover, effects of kidney function on outcomes in oncology is presented. In addition, nephrology services should better understand both the biology of malignancy with its treatment to become a valuable part treating team to yield the best possible outcome. It is important for nephrology services to be acknowledged and to take an active participation in care of oncology patients.

\section{INTRODUCTION}

In the XXI century patients with malignancy make up the most growing number of the subjects seen for nephrology consult and/or critical care nephrology services. The outstanding progress in the therapy of malignancy presents new possibilities and challenges for both nephrologists and medical oncologists. It is important for nephrology services to be acknowledged and to take an active participation in care of oncology patients. In addition, nephrology services should better understand both the biology of malignancy with its treatment to become a valuable part treating team to yield the best possible outcome.

A long time ago, the links between renal disease and malignancy were observed, however, quite recently their importance was recognized and 'new' subspecialty in nephrology, namely 'onconephrology' was established [1]. Chronic kidney disease-CKD is often diagnosed in the general population [2], however, the its incidence and prevalence among patients with malignancy was not extensively studied and data were limited. Half of the century ago, increased incidence of cancer in CKD patients has been discussed by Sutherland et al [3]. Other 
reports from the last century have also linked chronic kidney disease with an increased incidence of cancer [4-10]. In XXI century, Cengiz [11] reported that in the last 20 years, prevalence of solid tumors was $6.7 \%$ in the population of 2817 subjects with CKD, including 199 subjects on hemodialyses. It is of interest that $71 \%$ of the hemodialyzed patients were diagnosed with tumors in the first year of the therapy, while in $84 \%$ of patients with CKD, tumors were detected in less than 10 years after diagnosis of CKD. The most common were urologic malignancy followed by parathyroid adenoma and skin cancer in this population studied.

A plethora of renal problems may be found in patients with malignancy. They may influence not only their short-term outcomes but also the adequate therapy of the underlying oncological problem. Thus, all these kidney-related issues pose an important challenge for both specialities: oncology and nephrology. Indeed, the incidence rates for many malignancies are increased and amelioration in cancer mortality due to more effective chemotherapy, including targeted drugs, and treatment with stem cells, caused in a rise in population of cancer survivors [12]. Some of these survivors develop acute kidney injury-AKI or CKD due to either cancer (Figure 1) and/or its therapy (Figure 2) [13]. The kidneys may be thus directly or indirectly damaged by the malignancy or one or more of the novel therapeutics that prolong lives, however at the cost of developing AKI or CKD. In addition, multiorgan failure may be also seen in cancer patients. In consequence, they may require intensive care unit-ICU care and renal replacement therapy-RRT. In the setting of advanced malignancy complicated by multiorgan illness, appropriateness of aggressive treatment in "futile situations" and the role of palliative therapy remains the open question. Thus, care for oncology patients has become more specialized and complicated, requiring collaboration among nephrology, medical oncology, intensive therapy, and palliative care. Then the question of persistent therapy and end-of life care appears as well as the continuation of RRT in advanced malignancy.

\section{Acute kidney injury in patients with malignancy}

AKI and disturbances in electrolyte are the most common feature of kidney disease that are found in a patient with malignancy in a hospital setting. AKI in this population is linked with high morbidity and mortality. AKI incidence in these vulnerable patients depends upon type of malignancy (solid tumor or hematological malignancy), severity of underlying disease, complications of the disease and therapy. Several factors may potentiate the risk of AKI in these patients such as dehydration due to vomiting, diarrhea, obstruction of urinary tract, fluid and electrolyte disturbances, contrast agent

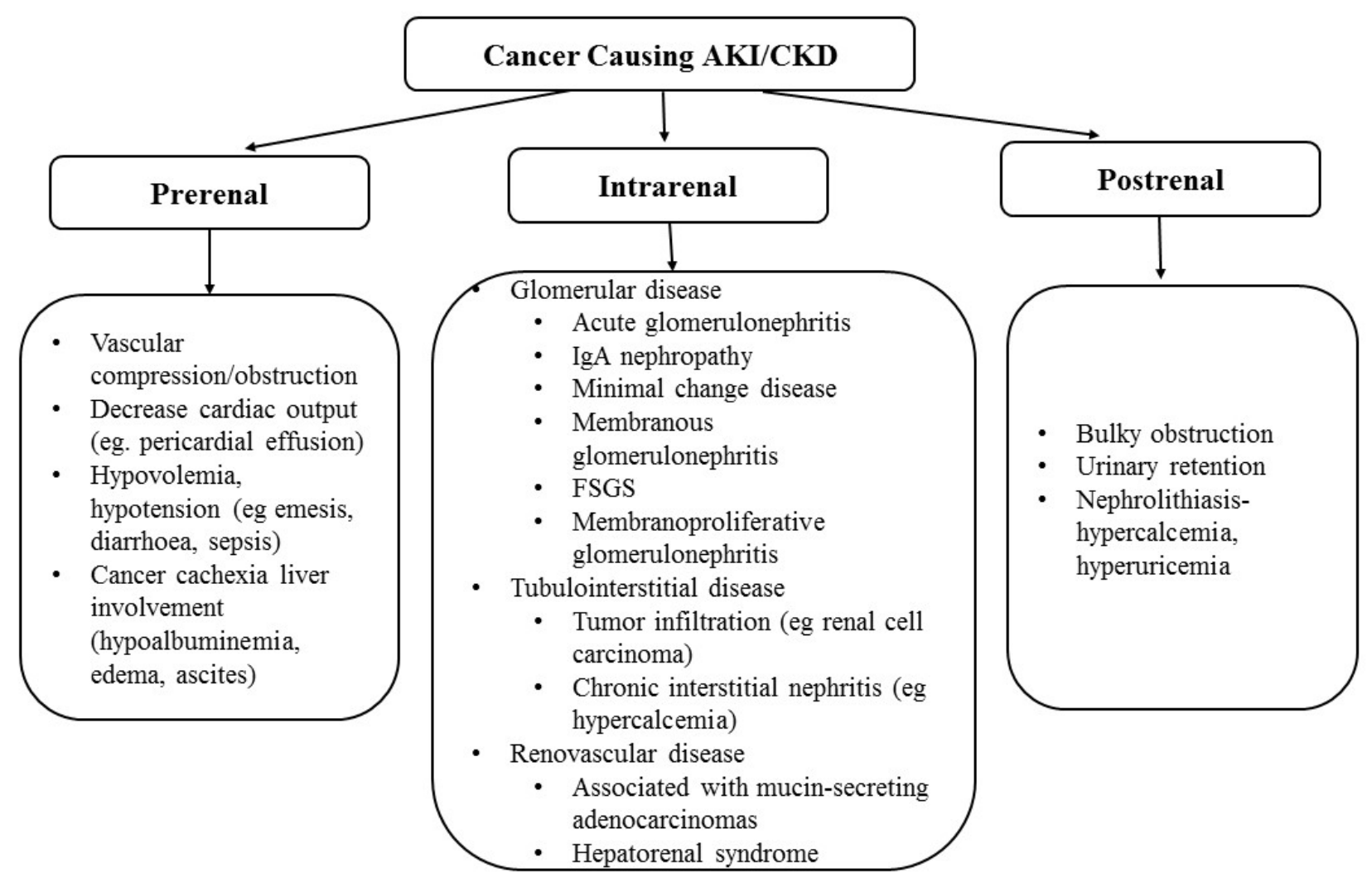

Figure 1: Cancer causing acute kidney injury (AKI) and/or chronic kidney disease (CKD). 
administration, nonsteroidal antiinflammatory drugs (NSAIDs), nephrotoxic antibiotics, renal toxicity of some chemotherapeutic and targeted drugs [14-17]. Moreover, critical illness in cancer patients is linked to the increased incidence of AKI and need for RRT relative to the population with similar severity of illness but without cancer [18-20]. AKI is this population is mainly due to therapy or malignancy itself [21]. AKI combined with critical illness in cancer patients yield worse outcomes, with mortality rates up to $85 \%$ in cases requiring renal replacement therapy [20]. Salahudeen et al. [22] studied 3558 subjects admitted to the Anderson Cancer Centre (Texas, USA) in a period of 3 months in 2006. They found that $12 \%$ were diagnosed with AKI. In the multivariate analysis, diabetes, chemotherapy, intravenous contrast administration, hyponatremia and use of antibiotic(s) were found to predict AKI development. Complications, comorbidities or exposures present in patients with malignancy before hospitalization posed higher risk of AKI than chemotherapy. Canet et al. [23] reported that AKI incidence in subjects with high-grade hematological malignancy was as high as $68.5 \%$ using RIFLE criteria (risk, injury, failure, loss of function, end-stage kidney disease-ESRD) with hypoperfusion, acute tubular necrosis, tumor lysis syndrome, nephrotoxins and hemophagocytic lymphohistiocytosis accounting for $91.5 \%$ of cases. Similarly to other AKI patients, impairment in kidney function previously considered trivial, has an equal prediction value of a unfavorable outcome in critically ill subjects with cancer [7]. Even a small increase in creatinine up to $10 \%(0.2 \mathrm{mg} / \mathrm{dL}-17.6 \mu \mathrm{mol} / \mathrm{L})$ was linked to extended ICU stay and higher death rates. Subjects with an elevated rise in serum creatinine ( $\mathrm{SCr}$ ), more than $25 \%$ within the first 72 hours of ICU admission had a 2-fold increase in mortality during hospitalization (14.3\% vs $30.1 \%, \mathrm{P}<0.001)$. This unfavorable outcome in patients with increased $\mathrm{SCr}$ is not solely due to the severity of disease or presence of other risk factors. It also should be taken into account, that the other comorbidities found in the patients with malignancy, may have a direct effect the on care of oncological subjects, type of the therapy and its efficacy. They also are predictive in patient outcomes, due to their possible interactions with the malignancy and developing frequently a more morbid condition than that caused by the malignancy alone [8-10]. Data on AKI epidemiology in oncological patients are limited, however, it appears that the incidence of AKI is at least 3 -fold higher in this population relative to that without cancer $[6,7,14,15]$. AKI in patients with malignancy may due either to ordinary causes, or there are unique or more common causes of AKI such as lymphomatous infiltration of the kidneys, cast nephropathy in multiple myeloma and monoclonal gammopathies, tumor lysis syndrome, mainly in malignancies with high tumor burden and rapid cell turnover [1, 17]. In addition, in patients treated with hematopoietic cell transplantation there are several unique causes of AKI $[1,17]$. Outcomes in cancer patients with AKI depend upon several factors. Soares et al. [24] reported that ICU, hospital, and 6-month mortalities in patients with malignancy and AKI admitted

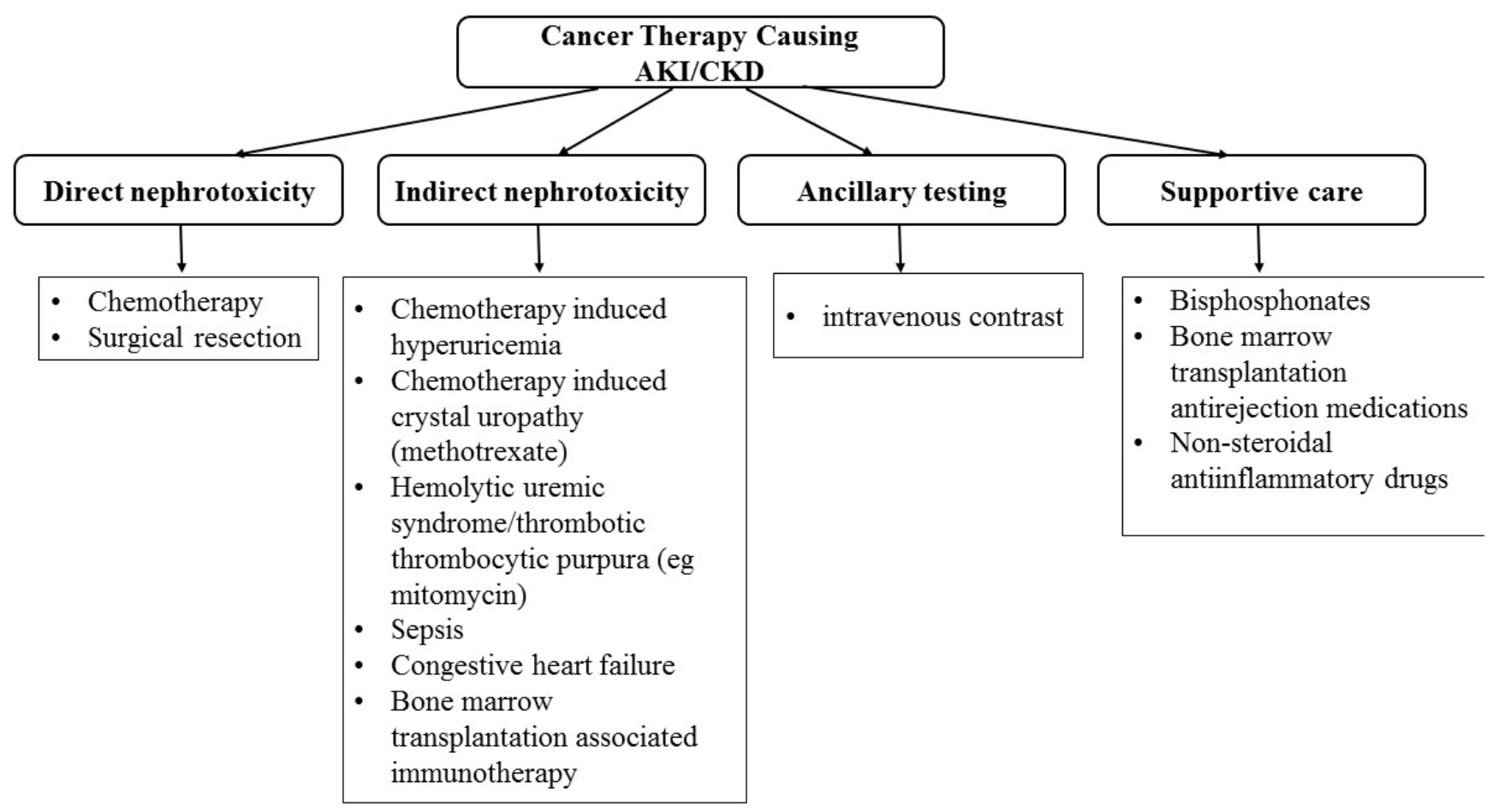

Figure 2: Cancer therapy causing acute kidney injury (AKI) and/or chronic kidney disease (CKD). 
to the ICU were $55 \%, 64 \%$, and $73 \%$, respectively. In this study, 6-month mortality was associated with an age of 60 years or older (HR 1.36; 95\% CI 1.00-1.84), an Eastern Cooperative Oncology Group- ECOG status of 2 to 4 (HR $1.66 ; 95 \%$ CI 1.22-2.26), more than 1 organ dysfunction (> organs, HR 4.07; 95\% CI 1.94-8.54), uncontrolled cancer (HR 1.61; 95\% CI 1.10-2.11), and severity of kidney failure (HR 1.77; 95\% CI 1.26-2.49) [24].

Kidneys clear same chemotherapeutics and AKI affect pharmacokinetics of these drugs. It may lead to their toxicity. On the other hand, RRT may lead to subtherapeutic levels of chemotherapeutics making treatment potentially ineffective. In addition, AKI may alter the levels of antibiotics, narcotics and other ancillary drugs leading to potential adverse effects. Thus, kidney function should be monitored carefully and drugs dose adjusted appropriately. In cases when not nephrotoxic drugs are available, it should be the preferred therapeutic option.

\section{Prerenal AKI}

AKI due to prerenal causes is a common finding in patients with malignancy [7]. In this population, AKI may be due to true dehydration, resulting from vomiting, diarrhea or sepsis. AKI due to dehydration related to malnutrition associated with antineoplastic therapy is commonly observed [7]. In sepsis, impaired perfusion and prerenal AKI may be due to hypotension and vasodilation due to either sepsis or administration of vasoconstrictory drugs, i.e. norepinephrine or vasopressin. In addition, prerenal AKI may be also caused by drugs such as diuretics, angiotensin II receptor blockers, angiotensinconverting enzyme inhibitors or NSAIDs used for either the cancer or other situations. Thus, physicians should be aware of the risks and benefits of continuation of these medications in oncological subjects. Prevention of the prerenal AKI is adequate hydration and avoidance or withdrawal of potentially nephrotoxic agents.

\section{Postrenal AKI}

Intratubular or extrarenal obstruction are frequent causes of AKI in patients with cancer [17, 25]. Conversely, malignancy should be considered in any patient not known to have cancer who presents with bilateral urinary tract obstruction that is not associated with urolithiasis. Obstruction could be either intratubular or extrarenal. Intratubular obstruction can be caused by uric acid crystals (in tumor lysis syndrome), light chain casts, or crystallization of certain drugs i.e high dose methotrexate. Obstruction of the bladder outlet or urether(s) is more frequent in malignancies relative to the general population [26]. Extrarenal obstruction can be caused by a wide range of malignancies i.e. bladdder, prostate, uterus and cervix cancers may cause obstruction of the urinary tract and postrenal AKI, and usually indicates metastatic disease $[17,25]$. Ureteral obstruction due to retroperitoneal fibrosis can be also secondary to malignancy. Patients with cancer may also develop urinary tract obstruction that is unrelated to the malignancy (eg, benign prostatic hypertrophy in men). The most common clinical presentation is anuria, flank pain, a palpable mass or palpable bladder. Urinary sediment is usually bland. In a case of partial obstruction, anuria may not be present. However, hyperkalemia with nonanion gap metabolic acidosis may suggest renal tubular acidosis due to obstruction [27]. On sonography, hydronephrosis or hydroureter are most common findings. However, in a case of obstructive AKI due to retroperitoneal fibrosis, malignancy or its treatment, hydronephrosis or hydroureter may not be present. It should be also stressed that radiotherapy of the pelvis or abdomen may also lead to retroperitoneal fibrosis. Percutaneous nephrostomy or stenting is performed to relief obstruction of the urinary tract, however, recovery is influenced by the severity and duration of the obstructive AKI.

\section{Renal AKI}

Glomerular, tubulointerstitial, and vascular diseases may cause renal function impairment in patients with malignancy. In differential diagnosis type of malignancy and type of chemotherapeutic agents are to be considered. The most common glomerular pathology in malignancy include vasculitis associated with antineutrophil cytoplasmic antibodies (ANCA), membrano-proliferative or membranous glomerulonephritis and thrombotic microangiopathy (TMA) $[17,25]$. Acute tubular necrosis due to ischemia may be caused by severe dehydration, hypotension or sepsis leading to prerenal AKI and then due to the severity and duration to intrinsic AKI. Chemotherapy-induced kidney injury are presented in the review elsewhere [28].

\section{Novel anti-cancer agents-related kidney problems}

It has been recognized that novel treatment with targeted drugs offer superior patient survival rates compared with standard chemotherapy. The most commonly used cancer therapies are targeted to proteasome, vascular endothelial growth factor-VEGR and its receptor- -VEGFR, epidermal growth factor receptor- EGFR, human epidermal growth factor receptor2-HER2, dimerizations of HER2, v-Raf murine sarcoma viral oncogene homolog B- BRAF, anaplastic lymphoma kinase-ALK, programmed cell death protein 1-PD-1 and its ligand PDL-1, receptor activator of nuclear factor kappa beta ligand- RANKL, and mammalian target of rapamycinmTOR. However, the downside of the targeted therapies and immunotherapy is unique adverse renal toxicity, well different from that of the conventional chemotherapy [29-31]. This toxicity was attributed to co-expression of 
same target molecules by both normal and cancer cells. VEGF pathway inhibitors include VEGF ligand inhibitors, which bind to and inhibit ligand binding to the VEGFR, thus preventing activation of the receptor as bevacizumab or targeted to VEGFR2 ramucirumab; and antiangiogenic small molecule tyrosine kinase inhibitors-TKIs (sunitinib, sorafenib, pazopanib, ponatinib, axitinib, cabozantinib, lenvatinib, vandetanib), which block the intracellular domain of the VEGFR and a soluble recombinant decoy that binds to circulating VEGF; aflibercept (VEGFTrap) [32]. The major renal adverse effect of this class is proteinuria, even nephrotic syndrome with hypertension as reviewed elsewhere [33]. In patients with proteinuria receiving VEGF-targeted agents, TMA, collapsing glomerulopathy, proliferative glomerulonephritis and isolated reports of cryoglobulinemic and immune complex glomerulonephritis were diagnosed on the kidney biopsy [34-36]. Antiangiogenic TKIs may cause also proteinuria, TMA, acute and chronic interstitial nephritis $[33,37]$. Monoclonal antibodies targeting the EGFR (cetuximab, panitumumab, necitumumab, matuzumab) are associated with the progressive development of hypomagnesemia due to renal magnesium wasting [38-40]. Immune checkpoint inhibitors (ICI) represent major improvements in patient outcomes in oncology. Cytotoxic T-lymphocyte antigen 4 -CTLA-4 and PD-1 are two essential immune checkpoint receptors. Ipilimumab and tremelimumab (anti-CTLA-4blocking antibodies) and pembrolizumab and nivolumab (antibodies targeting PD-1 receptors) have already been approved in several malignancies. Proteinuria, hypertension, renal failure and acute interstitial nephritis were reported in subjects given anti-PD-1 antibodies [4144]. In patients treated with CTLA-4 antibodies, nephrotic syndrome, acute tubular injury, acute tubular necrosis, acute interstitial nephritis and AKI have been reported [45-50]. The observed acute renal damage can be reversed upon drug discontinuation and introduction of systemic steroid therapy.

\section{Use of bisphosphonates in cancer-related bone disease}

Bisphosphonates are used to prevent bone resorption. Pamidronate and zoledronate are approved for bone events prevention in patients with advanced malignancy. Nephrotoxicity of bisphosphonates include mainly nephrotic syndrome, glomerulopathies such as collapsing focal segmental glomerulosclerosis (FSGS), FSGS-non specified and minimal change disease acute tubular necrosis and acute kidney injury [51-55].

\section{Contrast-induced nephropathy}

Contrast-induced nephropathy (CIN) is an important drawback following administration of intravascular iodinated contrast agent [56]. In the majority of studies, the definition of CIN is as an absolute $(\geq 0.5 \mathrm{mg} / \mathrm{dL})$ or relative $(\geq 25 \%)$ rise in $\mathrm{SCr}$ within $48-72 \mathrm{~h}$ after administration of iodinated contrast agent, when the rise in $\mathrm{SCr}$ could not be explained otherwise [56]. Patients with cancer are treated with variety of nephrotoxic medications (chemotherapeutics, targeted drugs, antibiotics, analgesics and others). Additionally, other problems like anemia, hypercalcemia and hyperuricemia may also contribute to development of kidney damage in patients with malignancy. Computed tomography with contrast (CT) appears to be standard and most common imaging procedure in oncology to monitor and evaluate the therapeutic response. Thus, the risk of CIN in patients with malignancy could be increased. Many cytotoxic and targeted medications as well as drugs for supportive care are contraindicated in the presence of impaired kidney function. Worsening of kidney function precludes or delays appropriate antineoplastic therapy. Cytotoxic drugs may be responsible for acute endothelial damage rather than toxic effects on kidney. Their administration can result in vasoconstriction, arterial hypertension and tissue ischemia as they effect the vasomotor activity of vascular smooth muscle via the nitric oxide synthesis, and adenosine and endothelin release. In turn, oxygen free radicals and lipid peroxidation may follow leading to inflammation, endothelial injury and thromboembolism [57-63]. Cytotoxic agents may affect endothelial and vascular structures leading to ischemic heart disease, cerebrovascular disease, venoocclusive syndrome, Raynaud's phenomenon and capillary leakage syndrome [64]. Bevacizumab was reported to influence significantly renal endothelium and vasculature [64]. There are several mechanisms of CIN development by contrast agents. They lower the glomerular filtration rate (GFR) and renal medullary blood flow as they exhibit vasoconstrictory effects on kidney vasculature [56-60]. Moreover, they are responsible for tissue ischemia/hypoxia due to increased adenosine and endothelin concentrations [65]. Inflammation due to renal tissue injury and free oxygen radical synthesis may also lead to CIN after administration of contrast agents [66, 67]. A few studies evaluated CIN prevalence in cancer patients. Cheruvu et al. [68], using the retrospective data of subjects with malignancy, reported CIN prevalence in $9 \%$ of the subjects with preexisting kidney disease (irreversible CIN was observed in half of these patients) and in approximately $5 \%$ of those without kidney disease. It should be stressed, that in their institution, a National Cancer Institute, they used iodixanol, an iso-osmolar, dimeric, non-ionic contrast agent in CKD patients [68]. In this population, many additional risk factors for CIN development were present and related to the underlying disease (ie, multiple myeloma and nephrotoxic chemotherapeutics) [68]. Cicin et al. [69] reported the 4.5 -fold higher risk of CIN in subjects undergoing $\mathrm{CT}$ within 45 days after the course of chemotherapy relative to those not given chemotherapy or undergoing CT more than 45 days after the course of chemotherapy. They used low-osmolar, non-ionic contrast agents i.e. iopromide $(428 \mathrm{mOsmol} / \mathrm{l})$ or iohexol (465 
mOsmol/1). They suggested that patients undergoing CT with contrast within 45 days after chemotherapy were at the increased risk for CIN. Among chemotherapeutics, only the combination of bevacizumab/irinotecan appeared to bear the increased risk for CIN. Ng et al. [70] assessed the admissions to an oncology ICU of 3,848 subjects and compared CT with and without contrast medium with no CT. They found that $\mathrm{SCr}$ increased in $55 \%$ of patients after CT (with and without contrast agent) [70]. No significant difference between the two groups (with and without contrast agent) was detected as a probable reflection of the critical illness in the studied population. The prevalence of CIN was approximately 16-17\%. Absolute change in $\mathrm{SCr}$ between matched CT groups (with and without contrast agent) did not differ significantly. The authors concluded that IV contrast agent administered to patients with relatively normal kidney function in oncologic ICU caused a rise in SCr. However, the increase in $\mathrm{SCr}$ was not beyond that of simply performing $\mathrm{CT}$ or of a matched non-CT group in ICU. Crucial studies were published by McDonald et al. [71-73] who questioned the concept of CIN after contrast media exposure. Over than 100000 patients, including cancer population were retrospectively analyzed in this multiple propensity score matched trials, each trial enrolled over 10000 patients. In the large, retrospective, single-center study, they observed equal risk of AKI among patients receiving contrast enhanced computed tomography if compared to unenhanced computed tomography. Systemic review published in 2013, based on studies concerning AKI incidence among patients underwent enhanced and unenhanced CT, showed similar risk of AKI in both group of patients [71]. Even the risk of dialysis and mortality was comparable in both groups [71]. Moos et al. [74] in the meta-analysis reported a low incidence of CIN after CT. Development of CIN was predicted by the presence of kidney failure, diabetes, cancer, old age and therapy with NSAIDs. They evaluated 42 publications with 18,790 subjects (mean age 61.5 years, ranged $38-83$ years), with mean baseline eGFR of $59.8 \mathrm{~mL} / \mathrm{min} / 1.73 \mathrm{~m}^{2}$ (range: 4 - $256 \mathrm{~mL} / \mathrm{min} / 1.73 \mathrm{~m}^{2}$ ). In $45.0 \%$ of patients eGFR was less than $60 \mathrm{~mL} / \mathrm{min} / 1.73 \mathrm{~m}^{2}$, $55.2 \%$ were hypertensive; $20.2 \%$ were diabetic (DM) and $6.5 \%$ suffered from congestive heart failure (CHF). They stressed that although many risk factors are mentioned in the guidelines, only a few predicted CIN development after IV iodinated contrast agent administration for CT, namely: kidney failure, DM, age $>65$ years and NSAIDs. Additionally, despite significant association between CIN development and cancer was revealed, the present guidelines did not contain such an information. The value gained and the risk incurred by imaging studies in general, and radiocontrast-enhanced imaging studies in particular, remain critically important questions in many medical and surgical subspecialties including oncology. Although data in oncology are very limited, it is suspected that, on the basis of existing assumptions regarding attributable risk, diagnostic studies and some interventions that might save or improve lives are being withheld from patients owing to an exaggerated fear of radiocontrast nephropathy. Therefore, the benefit of a contrast-enhanced study with the risk, likely low but likely not zero, of radiocontrast administration on the kidney should be carefully estimated as to date there have been no randomized studies of the risk of radiocontrast administration in oncology field.

\section{CKD in patients with malignancy}

\section{Prevalence of CKD in patients with malignancy}

In the last years, a remarkable number of targeted drugs have shown their efficacy and benefits in various malignancies together with improved outcomes such as progression-free and/or overall survivals. Prevalence CKD is reported to be high in patients with malignancy [75], but the renal effect of new targeted therapies have not been not widely studied. CKD prevalence of $\sim 33$ and $27 \%$, respectively, was reported by Dogan et al. [76] and Launay -Vacher et al. [77]. IRMA-1 (Insuffisance Rénale et Médicaments Anticancéreux; Renal Insufficiency and Anticancer Medications) study included 4684 subjects with malignancy. In this study, $50-60 \%$ of the subjects had an abnormal renal function (GFR $<90 \mathrm{ml} / \mathrm{min} / 1.73$ $\mathrm{m}^{2}$ ), whereas $\mathrm{SCr}$ was normal in most patients [50]. These results emphasize the CKD incidence is high in subjects with malignancy. In France, in the 'IRMA' studies, a prevalence of a GFR below $90 \mathrm{ml} / \mathrm{min} / 1.73 \mathrm{~m}^{2}$ was $52.9 \%$ in IRMA-1 [78] and 50.2\% in IRMA-2 [79], in a cohort of 5000 subjects with different types of malignancy. According to KDIGO (Kidney Disease Improving Global Outcomes) definition [80], the prevalence of stage 3 to $5 \mathrm{CKD}$, excluding RRT, was also high reaching $12.0 \%$ in IRMA-1 and $11.8 \%$ in IRMA-2, respectively [78, 79]. Huang et al. [81] reported that $87 \%$ patients with renal cancer, had eGFR $<90 \mathrm{ml} / \mathrm{min} / 1.73 \mathrm{~m}^{2}$. The study was performed in a cohort of 662 subjects with a renal cortical tumor subjected to either partial or radical nephrectomy. In addition, eGFR $<60 \mathrm{ml} / \mathrm{min} / 1.73 \mathrm{~m}^{2}$ was reported in $26 \%$ [81]. Prevalence of CKD ranged from $16.1 \%$ to $25.0 \%$ in patients with malignancy in Belgium [82], United States [83], and Japan [84]. In the IRMA-1 study, CKD was highly prevalent reaching approximately $50 \%$ in either breast, colorectal, lung, ovarian, or prostate cancers [85-87]. The Belgian Renal Insufficiency and Anticancer Medications (BIRMA)[82] study was a large, national, multicenter and retrospective trial. It was performed to evaluate CKD prevalence in Belgian patients with malignancy [82]. In addition to IRMA-1 study, the rationale for BIRMA trial was to describe the type and dosage of the antineoplastic therapy prescribed according to kidney function and to evaluate the interactions between kidney function and anemia, previous anticancer therapy, history of kidney disease, and metastases [82]. The study was performed on 1218 patients. Elevated 
$\operatorname{SCr}(\geq 1.2 \mathrm{mg} / \mathrm{dL})$ was found in $14.9 \%$ of patients, but in $64.0 \%$ of them eGFR was below $90 \mathrm{ml} / \mathrm{min} / 1.73 \mathrm{~m}^{2}$. In all, $78.6 \%$ of patients $(n=1087)$ were administered at least one drug subjected to dose adjustment and $78.1 \%$ received at least one drug known to be nephrotoxic. This is of interest, that $56.5 \%$ of patients with CKD treated with chemotherapeutics requiring dose adjustment in case of CKD, had no dose reduction [82]. From this study it appears, that prevalence of CKD is high in patients with malignancy and is routinely underestimated by clinicians as they assess kidney function using serum creatinine level only. Moreover, $80 \%$ of the patients were administered drugs with potential nephrotoxicity and/or for which dose had to be adjusted in CKD. Therefore, the dose of chemotherapeutics should be checked in advance by medical oncologists taking into account the actual kidney function. In the recent study, Yang and et al. [88] demonstrated that $32.4 \%$ of patients with newly diagnosed cancer exhibited chronic kidney disease. In addition, renal function was inversely related to all-cause mortality. Moreover, eGFR below $60 \mathrm{~mL} / \mathrm{min} / 1.73 \mathrm{~m}^{2}$ was an independent predictor of mortality relative to eGFR $\geq 60 \mathrm{~mL} / \mathrm{min} / 1.73 \mathrm{~m}^{2}$, and it was dependent upon cancer site. After adjustment for confounders, eGFR $<60$ $\mathrm{mL} / \mathrm{min} / 1.73 \mathrm{~m}^{2}$ was associated with higher mortality risk among patients with hematologic malignancy and gynecological cancer. They stressed that they enrolled incident rather than prevalent patients and eGFR was obtained at the time of diagnosis, to rule out the effect of anticancer treatment on kidney function.

\section{Associations between cancer and CKD}

Wong et al. [89] studied a cohort of 3654 subjects and assessed the relation between eGFR and risk of cancer. They found that in men, but not in women, with eGFR lower than $55 \mathrm{ml} / \mathrm{min} / 1.73 \mathrm{~m}^{2}$, a risk for cancer was significantly higher [89]. In particular, lung and urinary tract cancer risk raised by $29 \%$ for each $10 \mathrm{~mL}$ fall in eGFR (estimated by Modification of Diet in Renal Diseases-MDRD formula). Danish registry study assessed the risk for cancer over two 8-year periods of time: 19932000 and 2001-2008. The authors found that in the studied periods, the incidence of malignancy per year of risk did not increase significantly, $3.1 \%$ versus $2.6 \%$. However, the prevalence of cancer rose gradually by $35 \%$ from $10.4 \%$ in the earlier period to $14.0 \%$ in the later period [90]. The most common malignancies in this study were skin cancers (basal cell and squamous-cell), breast cancer, cervical cancer, melanoma, followed by colon, respiratory tract, bladder, prostate, and kidney cancers [91]. On the basis of these findings, it appears that CKD itself is a risk for cancer, dialyses or kidney transplantation, as reported previously $[92,93]$. In breast, colorectal, lung, ovarian, and skin cancers, prevalence of CKD was increased [9193] In addition, breast, cervix, colon, and kidney are more common in CKD than in the general population [91-93]. It is of importance that for these malignancies targeted drugs became available and introduced into the clinical practice. Therefore, the issue of renal safety is very important.

\section{Cancer and renal replacement therapy}

Patients on RRT are dying mainly due to o cardiovascular disease and infections, while malignancy is relatively common in this population. About $6 \%$ of the incident hemodialyzed subjects in the USA have malignancy as a comorbidity [94]. Despite the population of patients requiring RRT is growing and ESRD is associated with an increased risk of malignancy, data on the on the optimal management of ESRD patients with cancer is limited. Butler et al. [95] using US adult patients enrolled in Medicare's ESRD program hemodialyzed within the period from April 1, 1995, through December 31, 2010, assessed 5-year cumulative cancer incidence since RRT. They reported that 5-year cumulative incidence of any malignancy was $9.48 \%$ and was elevated for certain subgroups: elderly, non-Caucasians non-Latino, males, nondiabetics, recent hemodialysis therapy, and history of kidney transplant evaluation. They also suggested a high burden of malignancy in the hemodialyzed population compared to the US general population, as well as with the $4.4 \%$ estimate among US transplant recipients as reported by Hall et al [96]. Lin et al. [97] used the data from the Taiwan National Health Insurance Research Database on subjects who initially received RRT between January 1997 and December 2004. They showed that the RRT group revealed a significantly higher 7-year cancer incidence rate than did the general population and risk for blood, liver, colorectal, oral, breast, renal, upper urinary tract, and bladder cancer development was significantly higher than in the general population. In Europe, Bechade et al. [98] used the data from cancer registries and hospital databases in one French region and searched for subjects with an incident malignancy between 2001 and 2008 who started RRT. They found that the incidence rate of RRT in the population of incident malignancy was 370 per million population/year (74 events/199,809 personyears). Age-adjustment standardized incidence ratio was 1.26 , (95 \% CI $0.98-1.57, \mathrm{p}=0.55)$. In contrast to the American [95] and Taiwan [97] counterparts, they suggested that the standardized incidence ratio of chronic dialysis initiation was not significantly differed between patients with malignancy and the general population [98]. There are several explanations for increased cancer incidence in the dialysis population such as ESRD-associated immunodeficiency and nutritional abnormalities [99-109]. Interactions between immune dysfunctions due to of uremia and ESRD with established risk factors such as UV radiation, tobacco, or alcohol may also contribute to the excess cancer risk in CKD [100, 103]. Recently, there has been a focus on the potential role of erythropoietin-stimulating agents, commonly used to manage anemia; in carcinogenesis, they are 
known to activate erythropoietin receptors on the surface of cancer cells. Additionally, erythropoietin-induced angiogenesis may promote tumor growth [110, 111]. Nephrologists who care for ESRD population face the challenges including delays in diagnosis of malignancy, unclear utility of malignancy screening, and dilemmas in diagnostic imaging [112]. In addition, in a case of advanced or refractory malignancy, both nephrology and oncology specialists may cope with the issue of ethically complex palliative care as well as withholding of RRT [113-117]. There are several mechanisms to explain the higher increased incidence of malignancy in ESRD population. There are several confounding factors which may affect the diagnosis and evaluation of cancer in ESRD such as delayed symptomatic presentation, a nonvalidated and unclear utility of tumor markers, dilemmas in imaging studies, and lack of prognostic data. Several important cancer presentations may be omitted in ESRD such as hypercalcemia, hyperphosphatemia, pruritus, anemia with severity inadequate to the kidney function and oliguria/anuria [118]. Serum cancer antigen 125 (CA125) may be a useful tumor marker however, it can be elevated in ascites, even in non-malignant settings [119]. Although prostate-specific antigen (PSA) is not removed by dialysis, fluctuations and rises in PSA levels could be observed secondary to hemoconcentration or disturbances in binding proteins following RRT [120]. Imaging studies requiring contrast are commonly performed for diagnosis, staging, or monitoring of malignancy. As with iodinated contrast agents, the European Society of Urological Radiology (ESUR) does not recommend any specific timing for HD following nuclear magnetic resonance imaging with gadolinium.

There is uncertainty on validity of conventional prognostic factors and outcome data for specific malignancy in ESRD population on RRT due to the absence of randomized clinical trials. Several aspects of antineoplastic regimen in RRT are important to consider such as selection of chemotherapeutic agent, dose adjustment, timing of dialysis in relation to administration of chemotherapeutic agent, vascular access for RRT and chemotherapeutic regimen, type of dialysis and staff safety considerations. The kidney clearance of a cytotoxic drugs is important in dialyzed patients. RRT can affect clearance of chemotherapeutics in several ways than just a simple first-order kinetics. Cytotoxic agent could be cleared by dialysis. It may affect the dose given as well as the timing and characteristics of the subsequent dialysis. The preservation of vascular access for RRT is crucial and especially demanding in a patient receiving cytotoxic drugs, but the effects of quickly administered chemotherapeutics through an arterialized vein have not been adequately assessed. Thus insertion of the port for chemotherapy may be worth to consider, however, possible complications of having both port and central venous catheter, in particularly on the same site should be taken into account. Data on chemotherapeutic drugs in ESRD are very scarce. For some cytotoxic medications, it appears that ESRD subjects can tolerate standard treatment. It seems very important that a systematic approach to investigate anticancer treatment in the growing RRT population is of utmost importance, particularly for the frequent malignancies such as lung, breast, colorectal, and prostate cancers for which the data are in general under-represented relative to other less common cancers such as transitional cell cancer, cancer of the testis and leukemia.

\section{Assessment of kidney function in patients with malignancy}

Assessment of glomerular filtration rate is complex, cumbersome and time consuming to perform on everyday basis. However, SCr should be used to estimate GFR in subjects with stable kidney function [121]. Moreover, precise GFR is not required for most clinical settings and it is unrealistic. However, in some clinical situations it appears to be reasonable to consider measuring GFR i.e dose adjustment of medications, especially toxic medications with narrow therapeutic indices, such as chemotherapy. Inulin is the gold standard of exogenous filtration marker, however, using alternative filtration markers (such as radioactive or nonradioactive; iohexol, iothalamate, ethylenediaminetetraacetic acidEDTA or diethylenetriaminepentaacetate-DTPA), bolus administration of the marker (intravenous or subcutaneous), spontaneous bladder emptying and plasma clearance GFR could be estimated simpler and less cumbersome than inulin clearance [80]. At present, the most common methods utilized are the creatinine clearance and estimation formulas based upon SCr such as the Cockcroft-Gault formula, the Modification of Diet in Renal Disease (MDRD) study formula, and the Chronic Kidney Disease Epidemiology Collaboration (CKD-EPI) formula [80]. Both the creatinine clearance assessment and estimation formulas rely upon $\mathrm{SCr}$ as a marker of kidney function. Unfortunately, $\mathrm{SCr}$ is an unreliable marker during acute changes in renal function [122]. Firstly, using $\mathrm{SCr}$ to assess true kidney function has several limitations [123]. A significant decline in GFR can be observed before it is reflected in an increase $\mathrm{SCr}$ (up to 50\% of renal function could be lost before $\mathrm{SCr}$ might change). Secondly, SCr does not reflect renal function during acute changes until a steady state have been reached, which may last for several days. Moreover, $\mathrm{SCr}$ is a poor indicator for AKI due principally because it could not help to diagnose early AKI and differentiate the various causes of AKI. Concerning equations estimating GFR, within the $5^{\text {th }}$ and $95^{\text {th }}$ percentile for age, both MDRD and CockcroftGault formulas provide comparable data consistent with values obtained for age-specific historic inulin clearance [124]. The Cockcroft-Gault formula gave higher values 
at younger ages, and lower values in the older than 70 years than the obtained with the MDRD equation [125]. The CKD-EPI formula was formed to provide a more precise estimate of GFR among individuals with normal or only slightly declined GFR (i.e, $>60 \mathrm{~mL} / \mathrm{min}$ per 1.73 $\mathrm{m}^{2}$ ) [126]. Currently, CKD-EPI formula is recommended to assess kidney function, screening and diagnosis of CKD according to KDIGO guidelines [80]. However, this formula was not validated in cancer patients. It should also be stressed that people older than 65 years usually have, but not always lowered GFR [127, 128]. It may be explained by the presence of other comorbidities, which may influence GFR [129]. This is of particular interest in cancer patients. Drug dosing guidelines have historically been developed using the Cockcroft-Gault formula to assess kidney function. Most pharmacokinetic studies for drug dosing in renal disease were performed using the Cockcroft-Gault formula because it was recommended by the FDA (Food and Drug Administration) prior to publication of the MDRD study equation [130].

\section{Kidney function and risk of death in cancer}

Possible association between renal function and death in malignancy are not widely studied [131-137]. In some reports, inverse associations with different cutoff value of the eGFR and mortality were observed [131$134]$, whereas in others there were no relationships [135, 136]. In the recent study, Lichtman et al. [138] reported that after controlling for standard prognostic factors, renal function was not predictive of either overall survival or recurrence-free survival in subjects $>65$ years with early breast cancer regardless of regimen. It worth to stress that cancer itself may have a strong effect on mortality rather than an impaired renal function. Some studies suggested that the association of eGFR and mortality depend upon the type of cancer $[131,139]$. These inconsistencies may be due to the sample size in the various eGFR levels, threshold value of eGFR, formula used to assess eGFR, cancer stage, and follow-up periods, different population in regard to the treatment (treatment naive or treated patients). In the recent retrospective study on 9465 subjects with newly diagnosed malignancy, Yang et al. [88] reported that presence of a eGFR below 60 $\mathrm{mL} / \mathrm{min} / 1.73 \mathrm{~m} 2$ or proteinuria were associated with higher risk for all-cause death. In addition, subgroup analysis revealed that $\mathrm{eGFR}<60 \mathrm{~mL} / \mathrm{min} / 1.73 \mathrm{~m} 2$ was an independent predictor of mortality in patients with hematologic and gynecological malignancies, but not in those with other types of malignancy. In addition, proteinuria appeared as a risk for death among patients with digestive system cancer. It should be also pointed out that Yang et al. [88] enrolled incident rather than prevalent patients and eGFR by CKD-EPI, not MDRD was obtained at the time of diagnosis, thus they could rule out the impact of anticancer treatment on renal function. The authors also stressed that the prevalence of CKD was frequent $(32,4 \%)$ in patients with new diagnosis of malignancy. Proteinuria, being a risk factor for the progression of CKD should be assessed and monitored in cancer patients. This is crucial due to the potential effect of proteinuria on survival. As the data are limited and inconsistent, it appears that the mechanisms underlying the impact of renal function on mortality among patients with different primary cancer are complex and remain to be elucidated in large and prospective studies.

\section{Therapeutic implications of CKD presence in cancer patients}

It has been reported that incidence of CKD is high in cancer patients. It is essential to stress that $\mathrm{SCr}$ is not appropriate for assessment of kidney function. GFR is estimated by equations such as MDRD, also in subjects with a normal $\mathrm{SCr}$ and even on regular visits in subjects coming for routine check-ups without administration of antineoplastic medications. It should be also considered that oncology patients are still exposed to renal and extrarenal toxicity of non-antineoplastic medications prescribed for other reasons. Janus et al. [82] found that in $46.7 \%$ of the 120 subjects with a GFR below $60 \mathrm{ml} /$ $\mathrm{min} / 1.72 \mathrm{~m}^{2}$ and for which drug dosages were available in the medical file were administered at least one medication with an unadjusted dose in relation to kidney function. It is very important for clinicians to handle antineoplastic drugs properly in this population. Approximately 50\% of all chemotherapeutics are excreted predominantly by the kidneys in urine as unchanged drug or active metabolite(s), thus, any impairment in kidney function may lead to accumulation of potentially toxic metabolites and overdosage [78]. The dose of anticancer drugs in CKD patients should be adjusted to avoid severe toxicities [140]. In addition, using chemotherapeutics with potential nephrotoxicity will also require specific monitoring and, when available, specific prevention reducing the risk for nephrotoxicity, especially in patients with preexisting CKD [78]. It was shown very elegantly in the IRMA-1 study, where $79.9 \%$ patients were given at least one drug needed a dose adjustment or for which there were no data available for use in patients impaired kidney function [78]. In addition, $80.1 \%$ of the patients were administered at least one nephrotoxic medication [78]. In the BIRMA study, $24.8 \%$ patients were 'chemotherapy-naïve' and $75.2 \%$ patients were not 'chemotherapy-naïve' i.e. at least one antineoplastic agent was administered [82]. The prevalence of CKD in 'not chemotherapy-naïve' was a significantly higher than in 'chemotherapy-naïve' patients. In the BIRMA study, $54.3 \%$ of the 'chemotherapy-naïve' subjects exhibited a GFR below $90 \mathrm{~mL} / \mathrm{min} / 1.73 \mathrm{~m}^{2}$ relative to $67.1 \%$ in 'not chemotherapy-naïve' subjects $(\mathrm{P}<0.0001)$. Three IV bisphosphonates were prescribed in BIRMA study i.e. ibandronic, pamidronic, and zoledronic acid. 
The majority of subjects with bone metastases received zoledronic acid (220 patients). It is of interest that $67.3 \%$ had an impaired GFR and $50.9 \%$ of them were classified as having CKD [82]. In stage 2 CKD subjects, potential nephrotoxicity of the therapy is the important and relevant issue. It has been shown that preexisting impairment in kidney function is a risk factor for nephrotoxicity caused by anticancer treatment [141]. Thus, in patients with worsened kidney function, clinicians should take into account the potential risk of nephrotoxicity, and implement preventive measures whenever possible. However, in a case when administration of nephrotoxic agent is necessary, it is essential to adjust the dose, according to the kidney function and to follow the guidelines for the management of nephrotoxicity if available, as in a case of cisplatin [139]. In the BIRMA study, subjects with impaired kidney function were administered a mean of 1.2 nephrotoxic antineoplastic agent [82]. In addition, some patients were given nephrotoxic combination, exposing them to an elevated iatrogenic nephrotoxicity (i.e gemcitabine + cisplatine). Thus, it is essential to avoid (whenever possible), nephrotoxic associations of antineoplastic and other agents. In the BIRMA study, there are no data available on other potentially nephrotoxic drugs, i.e. pain killers, therefore it was not possible to assess the number of potentially nephrotoxic drugs (antineoplastic and others) administered in this study [82]. Therefore, they considered that the exposure to nephrotoxic agents was underestimated in the population studied. It is plausible that nephrotoxicity induced by antineoplastic agents, i.e. zoledronic acid, contribute to the increased prevalence of CKD, but other factors should be also taken into account. The prevalence of a decreased GFR $\left(<90 \mathrm{~mL} / \mathrm{min} / 1.73 \mathrm{~m}^{2}\right)$ was significantly increased in BIRMA relative to IRMA trial (64.0 vs $52.9 \%, \mathrm{P}<0.0001)$ [50] and when compared to the study of Dogan et al. [76]. It may be due the fact that different patient populations were studied. In BIRMA study, breast cancer patients constituted a high proportion, whereas Dogan et al. [76] included mainly patients with gastrointestinal cancers. In addition, age was also significantly different in these three studies. It is of utmost importance to be aware of the kidney function in subjects administered with nephrotoxic or potentially nephrotoxic agent, and to monitor kidney function regularly, before each course of chemotherapy. This problem was addressed recently in the CALGB (Cancer and Leukemia Group B) 49907 study assessing the effect of preexisting kidney function and five endpoints: toxicity, dose modification, therapy completion, relapse-free survival and overall survival in patients aged more than 65 years old with early breast cancer on routine treatment, i.e. cyclophosphamide / doxorubicin (AC) or cyclophosphamide / methotrexate / fluorouracilCMF over capecitabine. Lichtman et al. [138] reported that incidence of stage 3 or $4 \mathrm{CKD}$ was high reaching up to $72 \%$ for $\mathrm{CMF}, 64 \%$ for $\mathrm{AC}$ and $75 \%$ in capecitabine group. They also observed that baseline kidney function estimated using Cockcroft-Gault formula was highly related to the occurrence of nonhematologic toxicity for the AC regimen and very mildly for the capecitabine regimen, but not related for the CMF regimen [138]. There currently are no standard recommendations for cancer screening in the dialysis population (ie, NKFKDOQI [National Kidney Foundation-Kidney Disease Outcomes Quality Initiative] or KDIGO guidelines). In practice, screening for malignancy in dialysis subjects has been given with an individualized patient-focused approach on the basis of the patient's cancer risk factors, expected survival, and transplantation status [112]. CANcer and DialYsis (CANDY) is the retrospective multicenter study, on 178 chronic dialysis patients with malignancy. Majority of the patients in this study, received at least one chemotherapeutic agent requiring either dose adjustments $(72 \%)$ or adequate time of administration $(82 \%)$ [142]. Iatrogenic toxicity developed in $44 \%$ of the treated patients: $34 \%$ was related to agents needed dose adjustment, and $17 \%$ was attributed to the additional agents with no existing therapy recommendations in dialyzed population [142]. The authors stressed that evidence is lacking in regard to use of systemic chemotherapy in CKD including RRT and this led to the inappropriate use of chemotherapeutic drugs and lethal toxicity in this particular population. Boesler et al. [143] demonstrated that administration of chemotherapeutic agents is feasible in hemodialyzed patients without unpredictable severe unwanted effects. They reported that the dosages given were significantly higher relative to proposed adjustments according to Dettli's proportional dose reduction rule [144]. They administered additionally the dose calculated by Dettli's rule to supplement the agent cleared by hemodialysis. They concluded that chemotherapy was feasible, but selection of the appropriate dose still needed the decision of medical oncology and nephropharmacology specialists, as there were no algorithms and no evidence available.

\section{Kidney transplantation and cancer}

\section{Kidney recipients with a history of cancer}

Kidney allograft transplantation is the best available option of treatment for most patients with ESRD [145, 146]. As subjects with CKD often have comorbidities, including past malignancy [147-150], the assessment of potential renal allograft recipient should be efficient and cost effective. Generally, most clinical guidelines suggest a waiting period free of recurrence of two to five years for most patients with a history of carcinoma [151-156]. However, the questions on the sufficient time after treatment of the malignancy and waitlisting for kidney transplantation are still the matter of debate. It comes from the assumption that immunosuppression therapy may enhance development of micrometastasis 
[157] thus increase the risk of recurrence. Data on tumor recurrence after transplantation is scarce and tumor type is associated a marked variability in the likelihood of recurrence [158]. It determines the recommendations for cancer survivors taking into consideration patient and tumor characteristics [159, 160]. In general, patients with history of basal or squamous skin cancer, in situ bladder cancer, all noninvasive papillary tumors of the bladder, and asymptomatic solitary renal cell cancers $<5$ $\mathrm{cm}$ can be waitlisted without delay $[150,152,160]$. In a case of malignant melanoma, colorectal carcinoma other than in situ Duke's A or B1 carcinoma, invasive cervical cancer, breast cancer with regional node involvement, bilateral disease, or inflammatory histology five years without evidence of recurrence is required [150, 152, 160]. Patients with ductal carcinoma in situ may be waitlisted after two years' interval. The low recurrence rates (below 10\%) were reported for localized renal cell carcinoma (RCC); testicular, cervical, and thyroid cancers; and lymphomas (including Hodgkin and non-Hodgkin lymphoma, higher recurrence rates (between 10 and 25\%) were noted for uterus, colon, prostate, and breast cancer and Wilms tumor, while the highest rates (over 25\%) were recorded for bladder carcinoma, advanced renal cell carcinoma, sarcomas, myelomas, and both melanoma and nonmelanoma skin cancers $[159,160]$.

\section{Oncological therapy in kidney allograft recipients}

Solid organ transplantation is associated with higher incidence of malignancy development relative to the general population [161] and several, but not all, studies have demonstrated increased cancer-related mortality among transplant recipients [162-164]. This excessive death rate in organ transplant recipients may be due to previous malignancy as well as to the fact that immunosuppressive therapy may promote more aggressive cancer development due to the loss of immune surveillance and/or due to the concern of organ rejection $[153,165]$. Thus, patients are offered less aggressive anticancer treatment $[153,165]$. Controversies existing around cancer screening in kidney transplant recipients in regard to reduced life expectancy and competing causes of death were presented elegantly by Acuna et al. [166] in systematic review of clinical practice guidelines. Oncological management in kidney transplant recipients is challenging and results from the balance between treatment of the malignancy and maintenance of a sufficient graft function. Recently, Wanchoo et al. [167] discussed the use of immune checkpoint inhibitors (ICI) in kidney transplant recipients. They summarized the 8 published cases when ICI were used in kidney transplant patients. They stressed that the transplant community should take into account the potential risk of rejection in renal allograft recipients treated with ICI. They also presented a novel strategy to prevent rejection in transplant recipients receiving PD-1 inhibitors using pre-emptive steroids and sirolimus. However, there is not enough data to give specific recommendations for oncology treatment in kidney transplant recipients. Each case should be considered individually and decision should be based on the patient's priority after receiving consultation from oncologist and transplant physician. The potential for graft loss needs to be weighed against the natural history and stage of the malignancy. The reasonable approach is to diminish immunosuppression, and consider switch into a mammalian target of rapamycin inhibitor [168]. In some case discontinuation of immunosuppression may be appropriate.

\section{SUMMARY}

Increased incidence of CKD, in particular, in the elderly, are of utmost importance. Many antineoplastic agents are cleared primarily by the kidneys as unchanged drugs or active metabolites. Therefore, a decline in kidney function can potentially lead to alterations in pharmacokinetics, elevated blood levels of the drugs, and increased toxicity. It has been shown that a remarkable number of CKD subjects treated with chemotherapy require dose reduction in case of $\mathrm{CKD}$, but they are not administered the adjusted dose [82]. Thus, it should be stressed that CKD is underrecognized problem in oncology population and eGFR is to be assessed simultaneously, not only in oncology ward but also in every department. This is due to the fact that patients are getting older, have more comorbidities, are administered more potentially nephrotoxic drugs and undergone more potentially nephrotoxic procedures such as percutaneous coronary interventions-PCI or CT with IV contrast agent etc. [169]. It is of utmost importance to be aware of the kidney function in patients receiving nephrotoxic or potentially nephrotoxic agent and to monitor kidney function regularly, before each course of chemotherapy. Oncologists should adjust the dose of cytotoxic drugs according to actual kidney function. Besides, in patients treated with nephrotoxic chemotherapeutic agents in particular with preexisting impairment of kidney function, the necessity of concomitant drugs should be carefully evaluated i.e.NSAIDS. They should be avoided, if possible, as they may contribute to the nephrotoxicity of chemotherapeutics.

\section{Abbreviations}

AC-cyclophosphamide/doxorubicine, AKI- acute kidney injury, ALK-anaplastic lymphoma kinase), BIRMA-Belgian Renal Insufficiency and Anticancer Medications, BRAF- v-Raf murine sarcoma viral oncogene homolog B)CALGB-Cancer and Leukemia Group B, CI- confidence interval, CIN- contrast-induced nephropathy, CHF- chronic heart failure, CKD- chronic 
kidney disease, CKD-EPI -chronic kidney diseaseepidemiological collaboration, CMF-cyclophosphamide/ methotrexate/ fluorouracil- CT- computed tomography, CTLA-4- cytotoxic T-lymphocyte antigen 4, DM- diabetes mellitus, DTPA- diethylene-triamine-pentaacetate, ECOG- Eastern Cooperative Oncology Group, EDTAethylenediaminetetraacetic acid, ESRD- end-stage renal disease, ESUR-European Society of Urological Radiology, eGFR- estimated glomerular filtration rate, EGFR- epidermal growth factor receptor), FDAFood and Drug Administration, FSGS-focal segmental glomerulosclerosis, HER2 - human epidermal growth factor receptor-2, HR-hazard ratio, ICI- immune checkpoint inhibitors, ICU- intensive care unit, IRMAInsuffisance Rénale et Médicaments Anticancéreux; Renal Insufficiency and Anticancer Medications, IVintravenous, KDIGO- Kidney Disease: Improving Global Outcomes, MDRD- Modification of Diet in Renal Disease, mTOR- mammalian target of rapamycin, NKFKDOQI-National Kidney Foundation-Kidney Disease Outcomes Quality Initiative, NSAIDs non-steroidal antiinflammatory drugs OR-odds ratio, PCI-percutaneous coronary interventions, PD-1-programmed cell death protein 1, PDL-1 igand of programmed cell death protein 1, RANKL (receptor activator of nuclear factor kappa beta ligand), PSA- prostate-specific antigen, RCC- renal cell carcinoma, RIFLE- risk, injury, failure, loss of function, end-stage kidney disease), RRT- renal replacement therapy, TKI- tyrosine kinase inhibitor, TMA- thrombotic microangiopathy, VEGR- vascular endothelial growth factor, VEGFR -vascular endothelial growth factor receptor.

\section{CONFLICTS OF INTEREST}

The authors declared no conflicts of interest. The study had no funding.

\section{REFERENCES}

1. Salahudeen AK, Bonventre JV. Onconephrology: the latest frontier in the war against kidney disease. J Am Soc Nephrol. 2013; 24: 26-30. doi: 10.1681/ASN.2012070690.

2. Jones CA, McQuillan GM, Kusek JW, Eberhardt MS, Herman WH, Coresh J, Salive M, Jones CP, Agodoa LY. Serum creatinine levels in the US population: third National Health and Nutrition Examination Survey. Am J Kidney Dis. 1998; 32: 992-9.

3. Sutherland GA, Glass J, Gabriel R. Increased incidence of malignancy in chronic renal failure. Nephron. 1977; 18: 182-4.

4. Denker B, Robles-Osorio ML, Sabath E. Recent advances in diagnosis and treatment of acute kidney injury in patients with cancer. Eur J Intern Med. 2011; 22: 348-54. doi: 10.1016/j.ejim.2011.02.002.
5. Lameire N, Van Biesen W, Vanholder R. Electrolyte disturbances and acute kidney injury in patients with cancer. Semin Nephrol. 2010; 30: 534-47. doi: 10.1016/j. semnephrol.2010.09.002.

6. Salahudeen AK, Doshi SM, Pawar T, Nowshad G, Lahoti A, Shah P. Incidence rate, clinical correlates, and outcomes of AKI in patients admitted to a comprehensive cancer center. Clin J Am Soc Nephrol. 2013; 8: 347-54. doi: 10.2215/ CJN.03530412.

7. Samuels J, Ng CS, Nates J, Price K, Finkel K, Salahudeen A, Shaw A. Small increases in serum creatinine are associated with prolonged ICU stay and increased hospital mortality in critically ill patients with cancer. Support Care Cancer. 2011; 19: 1527-32. doi: 10.1007/s00520-010-0978-7.

8. Janssen-Heijnen ML, Maas HA, Houterman S, Lemmens VE, Rutten HJ, Coebergh JW. Comorbidity in older surgical cancer patients: influence on patient care and outcome. Eur J Cancer. 2007; 43: 2179-93. doi: 10.1016/j.ejca.2007.06.008.

9. Hunter C, Johnson K, Muss H, Satariano W. Comorbidities and cancer. In: Hunter C, Johnson K, Muss H, editors. Cancer in the Elderly. New York: Dekker, M; 2000. p. 477-500.

10. Yung KC, Piccirillo JF. The incidence and impact of comorbidity diagnosed after the onset of head and neck cancer. Arch Otolaryngol Head Neck Surg. 2008; 134: 1045-9. doi: 10.1001/archotol.134.10.1045.

11. Cengiz K. Increased incidence of neoplasia in chronic renal failure (20-year experience). Int Urol Nephrol. 2002; 33: 121-6.

12. National Cancer Institute. Surveillance Epidemiology and End Results: SEER stat fact sheets: All sites. Available at: http://seer.cancer.gov/statfacts/html/all.html. Accessed January 16, 2017.

13. National Cancer Institute: Find cancer statistics. Available at: www.cancer.gov/statistics/find. Accessed January 16, 2017.

14. Christiansen CF, Johansen MB, Langeberg WJ, Fryzek JP, Sorensen HT. Incidence of acute kidney injury in cancer patients: a Danish population-based cohort study. Eur J Intern Med. 2011; 22: 399-406. doi: 10.1016/j. ejim.2011.05.005.

15. Lahoti A, Nates JL, Wakefield CD, Price KJ, Salahudeen AK. Costs and outcomes of acute kidney injury in critically ill patients with cancer. J Support Oncol. 2011; 9: 149-55.

16. Wilson FP, Berns JS. Onco-nephrology: tumor lysis syndrome. Clin J Am Soc Nephrol. 2012; 7: 1730-9. doi: 10.2215/CJN.03150312.

17. Lam AQ, Humphreys BD. Onco-nephrology: AKI in the cancer patient. Clin J Am Soc Nephrol. 2012; 7: 1692-700. doi: 10.2215/CJN.03140312.

18. Benoit DD, Hoste EA, Depuydt PO, Offner FC, Lameire NH, Vandewoude KH, Dhondt AW, Noens LA, Decruyenaere JM. Outcome in critically ill medical patients treated with renal replacement therapy for acute renal 
failure: comparison between patients with and those without haematological malignancies. Nephrol Dial Transplant. 2005; 20: 552-8. doi: 10.1093/ndt/gfh637.

19. Darmon M, Thiery G, Ciroldi M, de Miranda S, Galicier L, Raffoux E, Le Gall JR, Schlemmer B, Azoulay E. Intensive care in patients with newly diagnosed malignancies and a need for cancer chemotherapy. Crit Care Med. 2005; 33: 2488-93.

20. Darmon M, Ciroldi M, Thiery G, Schlemmer B, Azoulay E. Clinical review: specific aspects of acute renal failure in cancer patients. Crit Care. 2006; 10: 211. doi: 10.1186/ cc4907.

21. Lameire N, Van Biesen W, Vanholder R. Acute renal problems in the critically ill cancer patient. Curr Opin Crit Care. 2008; 14: 635-46. doi: 10.1097/ MCC.0b013e32830ef70b.

22. Lameire N. Nephrotoxicity of recent anti-cancer agents. Clin Kidney J. 2014; 7: 11-22. doi: 10.1093/ckj/sft135.

23. Canet E, Zafrani L, Lambert J, Thieblemont C, Galicier L, Schnell D, Raffoux E, Lengline E, Chevret S, Darmon M, Azoulay E. Acute kidney injury in patients with newly diagnosed high-grade hematological malignancies: impact on remission and survival. PLoS One. 2013; 8: e55870. doi: 10.1371/journal.pone.0055870.

24. Soares M, Salluh JI, Carvalho MS, Darmon M, Rocco JR, Spector N. Prognosis of critically ill patients with cancer and acute renal dysfunction. J Clin Oncol. 2006; 24: 4003 10. doi: 10.1200/JCO.2006.05.7869.

25. Campbell GA, Hu D, Okusa MD. Acute kidney injury in the cancer patient. Adv Chronic Kidney Dis. 2014; 21: 64-71. doi: 10.1053/j.ackd.2013.08.002.

26. Humphreys BD, Soiffer RJ, Magee CC. Renal failure associated with cancer and its treatment: an update. J Am Soc Nephrol. 2005; 16: 151-61. doi: 10.1681/ ASN.2004100843

27. Batlle DC, Arruda JA, Kurtzman NA. Hyperkalemic distal renal tubular acidosis associated with obstructive uropathy. N Engl J Med. 1981; 304: 373-80. doi: 10.1056/ NEJM198102123040701.

28. Malyszko J, Kozlowska K, Kozlowski L, Malyszko J. Nephrotoxicity of anticancer treatment. Nephrol Dial Transplant. 2016. Epub ahead of print.

29. Perazella MA. Checkmate: kidney injury associated with targeted cancer immunotherapy. Kidney Int. 2016; 90: 4746. doi: 10.1016/j.kint.2016.05.024.

30. Izzedine H, Perazella MA. Adverse kidney effects of epidermal growth factor receptor inhibitors. Nephrol Dial Transplant. 2017. doi: 10.1093/ndt/gfw467.

31. Izzedine $\mathrm{H}$, Mateus $\mathrm{C}$, Boutros $\mathrm{C}$, Robert $\mathrm{C}$, Rouvier $\mathrm{P}$, Amoura Z, Mathian A. Renal effects of immune checkpoint inhibitors. Nephrol Dial Transplant. 2016. doi: 10.1093/ndt/ gfw382.
32. Launay-Vacher V, Aapro M, De Castro G Jr, Cohen E, Deray G, Dooley M, Humphreys B, Lichtman S, Rey J, Scotte F, Wildiers H, Sprangers B. Renal effects of molecular targeted therapies in oncology: a review by the Cancer and the Kidney International Network (C-KIN). Ann Oncol. 2015; 26: 1677-84. doi: 10.1093/annonc/mdv136.

33. Launay-Vacher V, Deray G. Hypertension and proteinuria: a class-effect of antiangiogenic therapies. Anticancer Drugs. 2009; 20: 81-2. doi: 10.1097/CAD.0b013e3283161012.

34. Van Cutsem E, Tabernero J, Lakomy R, Prenen H, Prausova J, Macarulla T, Ruff P, van Hazel GA, Moiseyenko V, Ferry $\mathrm{D}$, McKendrick J, Polikoff J, Tellier A, et al. Addition of aflibercept to fluorouracil, leucovorin, and irinotecan improves survival in a phase III randomized trial in patients with metastatic colorectal cancer previously treated with an oxaliplatin-based regimen. J Clin Oncol. 2012; 30: 3499506. doi: 10.1200/JCO.2012.42.8201.

35. Eremina V, Jefferson JA, Kowalewska J, Hochster H, Haas M, Weisstuch J, Richardson C, Kopp JB, Kabir MG, Backx PH, Gerber HP, Ferrara N, Barisoni L, et al. VEGF inhibition and renal thrombotic microangiopathy. N Engl J Med. 2008; 358: 1129-36. doi: 10.1056/NEJMoa0707330.

36. George BA, Zhou XJ, Toto R. Nephrotic syndrome after bevacizumab: case report and literature review. Am J Kidney Dis. 2007; 49: e23-9. doi: 10.1053/j. ajkd.2006.11.024.

37. Usui J, Glezerman IG, Salvatore SP, Chandran CB, Flombaum CD, Seshan SV. Clinicopathological spectrum of kidney diseases in cancer patients treated with vascular endothelial growth factor inhibitors: a report of 5 cases and review of literature. Hum Pathol. 2014; 45: 1918-27. doi: 10.1016/j.humpath.2014.05.015.

38. Tejpar S, Piessevaux H, Claes K, Piront P, Hoenderop JG, Verslype C, Van Cutsem E. Magnesium wasting associated with epidermal-growth-factor receptor-targeting antibodies in colorectal cancer: a prospective study. Lancet Oncol. 2007; 8: 387-94. doi: 10.1016/S1470-2045(07)70108-0.

39. Kelly RJ, Billemont B, Rixe O. Renal toxicity of targeted therapies. Target Oncol. 2009; 4: 121-33. doi: 10.1007/ s11523-009-0109-x.

40. Groenestege WM, Thebault S, van der Wijst J, van den Berg D, Janssen R, Tejpar S, van den Heuvel LP, van Cutsem E, Hoenderop JG, Knoers NV, Bindels RJ. Impaired basolateral sorting of pro-EGF causes isolated recessive renal hypomagnesemia. J Clin Invest. 2007; 117: 2260-7. doi: 10.1172/JCI31680.

41. Topalian SL, Hodi FS, Brahmer JR, Gettinger SN, Smith DC, McDermott DF, Powderly JD, Carvajal RD, Sosman JA, Atkins MB, Leming PD, Spigel DR, Antonia SJ, et al. Safety, activity, and immune correlates of anti-PD-1 antibody in cancer. N Engl J Med. 2012; 366: 2443-54. doi: 10.1056/NEJMoa1200690.

42. Brahmer JR, Drake CG, Wollner I, Powderly JD, Picus J, Sharfman WH, Stankevich E, Pons A, Salay TM, 
McMiller TL, Gilson MM, Wang C, Selby M, et al. Phase I study of single-agent anti-programmed death-1 (MDX1106) in refractory solid tumors: safety, clinical activity, pharmacodynamics, and immunologic correlates. J Clin Oncol. 2010; 28: 3167-75. doi: 10.1200/JCO.2009.26.7609.

43. Hamid O, Robert C, Daud A, Hodi FS, Hwu WJ, Kefford R, Wolchok JD, Hersey P, Joseph RW, Weber JS, Dronca R, Gangadhar TC, Patnaik A, et al. Safety and tumor responses with lambrolizumab (anti-PD-1) in melanoma. N Engl J Med. 2013; 369: 134-44. doi: 10.1056/NEJMoa1305133.

44. Hofmann L, Forschner A, Loquai C, Goldinger SM, Zimmer L, Ugurel S, Schmidgen MI, Gutzmer R, Utikal JS, Goppner D, Hassel JC, Meier F, Tietze JK, et al. Cutaneous, gastrointestinal, hepatic, endocrine, and renal side-effects of anti-PD-1 therapy. Eur J Cancer. 2016; 60: 190-209. doi: 10.1016/j.ejca.2016.02.025.

45. Shirali AC, Perazella MA, Gettinger S. Association of acute interstitial nephritis with programmed cell death 1 inhibitor therapy in lung cancer patients. Am J Kidney Dis. 2016; 68: 287-91. doi: 10.1053/j.ajkd.2016.02.057.

46. Fadel F, El Karoui K, Knebelmann B. Anti-CTLA4 antibody-induced lupus nephritis. N Engl J Med. 2009; 361: 211-2. doi: 10.1056/NEJMc0904283.

47. Forde PM, Rock K, Wilson G, O'Byrne KJ. Ipilimumabinduced immune-related renal failure--a case report. Anticancer Res. 2012; 32: 4607-8.

48. Voskens CJ, Goldinger SM, Loquai C, Robert C, Kaehler KC, Berking C, Bergmann T, Bockmeyer CL, Eigentler T, Fluck M, Garbe C, Gutzmer R, Grabbe S, et al. The price of tumor control: an analysis of rare side effects of anti-CTLA-4 therapy in metastatic melanoma from the ipilimumab network. PLoS One. 2013; 8: e53745. doi: 10.1371/journal.pone.0053745.

49. Chmiel KD, Suan D, Liddle C, Nankivell B, Ibrahim R, Bautista C, Thompson J, Fulcher D, Kefford R. Resolution of severe ipilimumab-induced hepatitis after antithymocyte globulin therapy. J Clin Oncol. 2011; 29: e237-40. doi: 10.1200/JCO.2010.32.2206.

50. Cortazar FB, Marrone KA, Troxell ML, Ralto KM, Hoenig MP, Brahmer JR, Le DT, Lipson EJ, Glezerman IG, Wolchok J, Cornell LD, Feldman P, Stokes MB, et al. Clinicopathological features of acute kidney injury associated with immune checkpoint inhibitors. Kidney Int. 2016; 90: 638-47. doi: 10.1016/j.kint.2016.04.008.

51. Markowitz GS, Appel GB, Fine PL, Fenves AZ, Loon NR, Jagannath S, Kuhn JA, Dratch AD, D'Agati VD. Collapsing focal segmental glomerulosclerosis following treatment with high-dose pamidronate. J Am Soc Nephrol. 2001; 12: 1164-72.

52. Sauter M, Julg B, Porubsky S, Cohen C, Fischereder M, Sitter T, Schlondorff D, Grone HJ. Nephrotic-range proteinuria following pamidronate therapy in a patient with metastatic breast cancer: mitochondrial toxicity as a pathogenetic concept? Am J Kidney Dis. 2006; 47: 107580. doi: 10.1053/j.ajkd.2006.02.189.

53. Kunin M, Kopolovic J, Avigdor A, Holtzman EJ. Collapsing glomerulopathy induced by long-term treatment with standard-dose pamidronate in a myeloma patient. Nephrol Dial Transplant. 2004; 19: 723-6.

54. Jia N, Cormack FC, Xie B, Shiue Z, Najafian B, Gralow JR. Collapsing focal segmental glomerulosclerosis following long-term treatment with oral ibandronate: case report and review of literature. BMC Cancer. 2015; 15: 535. doi: 10.1186/s12885-015-1536-y.

55. Gokden N, Zangari M, Elici F, Barlogie B, Kumar J. Potential effect of zoledronate therapy in heavy proteinuria. Clin Nephrol. 2007; 67: 263-5.

56. Mehran R, Nikolsky E. Contrast-induced nephropathy: definition, epidemiology, and patients at risk. Kidney Int Suppl. 2006: S11-5. doi: 10.1038/sj.ki.5000368.

57. Arakawa K, Suzuki H, Naitoh M, Matsumoto A, Hayashi K, Matsuda H, Ichihara A, Kubota E, Saruta T. Role of adenosine in the renal responses to contrast medium. Kidney Int. 1996; 49: 1199-206.

58. Workman RJ, Shaff MI, Jackson RV, Diggs J, Frazer MG, Briscoe C. Relationship of renal hemodynamic and functional changes following intravascular contrast to the renin-angiotensin system and renal prostacyclin in the dog. Invest Radiol. 1983; 18: 160-6.

59. Seeliger E, Flemming B, Wronski T, Ladwig M, Arakelyan K, Godes M, Mockel M, Persson PB. Viscosity of contrast media perturbs renal hemodynamics. J Am Soc Nephrol. 2007; 18: 2912-20. doi: 10.1681/ASN.2006111216.

60. Gill RW. Doppler ultrasound--physical aspects. Semin Perinatol. 1987; 11: 292-9.

61. Murphy SW, Barrett BJ, Parfrey PS. Contrast nephropathy. J Am Soc Nephrol. 2000; 11: 177-82.

62. Lancelot E, Idee JM, Couturier V, Vazin V, Corot C. Influence of the viscosity of iodixanol on medullary and cortical blood flow in the rat kidney: a potential cause of nephrotoxicity. J Appl Toxicol. 1999; 19: 341-6.

63. Grabowski EF, Jang IK, Gold H, Head C, Benoit SE, Michelson AD. Variability of platelet degranulation by different contrast media. Acad Radiol. 1996; 3: S485-7.

64. Soultati A, Mountzios G, Avgerinou C, Papaxoinis G, Pectasides D, Dimopoulos MA, Papadimitriou C. Endothelial vascular toxicity from chemotherapeutic agents: preclinical evidence and clinical implications. Cancer Treat Rev. 2012; 38: 473-83. doi: 10.1016/j.ctrv.2011.09.002.

65. Heyman SN, Reichman J, Brezis M. Pathophysiology of radiocontrast nephropathy: a role for medullary hypoxia. Invest Radiol. 1999; 34: 685-91.

66. Baliga R, Ueda N, Walker PD, Shah SV. Oxidant mechanisms in toxic acute renal failure. Am J Kidney Dis. 1997; 29: 465-77. 
67. Moreau JF, Droz D, Sabto J, Jungers P, Kleinknecht D, Hinglais N, Michel JR. Osmotic nephrosis induced by water-soluble triiodinated contrast media in man. A retrospective study of 47 cases. Radiology. 1975; 115: 32936. doi: $10.1148 / 115.2 .329$.

68. Cheruvu B, Henning $\mathrm{K}$, Mulligan J, Klippenstein D, Lawrence D, Gurtoo L, Gottlieb RH. Iodixanol: risk of subsequent contrast nephropathy in cancer patients with underlying renal insufficiency undergoing diagnostic computed tomography examinations. J Comput Assist Tomogr. 2007; 31: 493-8. doi: 10.1097/ rct.0b013e31802e29d9.

69. Cicin I, Erdogan B, Gulsen E, Uzunoglu S, Sut N, Turkmen E, Kodaz H, Ustundag S. Incidence of contrastinduced nephropathy in hospitalised patients with cancer. Eur Radiol. 2014; 24: 184-90. doi: 10.1007/ s00330-013-2996-6.

70. Ng CS, Shaw AD, Bell CS, Samuels JA. Effect of IV contrast medium on renal function in oncologic patients undergoing CT in ICU. AJR Am J Roentgenol. 2010; 195: 414-22. doi: 10.2214/AJR.09.4150.

71. McDonald JS, McDonald RJ, Comin J, Williamson EE, Katzberg RW, Murad MH, Kallmes DF. Frequency of acute kidney injury following intravenous contrast medium administration: a systematic review and metaanalysis. Radiology. 2013; 267: 119-28. doi: 10.1148/ radiol.12121460.

72. McDonald JS, McDonald RJ, Carter RE, Katzberg RW, Kallmes DF, Williamson EE. Risk of intravenous contrast material-mediated acute kidney injury: a propensity scorematched study stratified by baseline-estimated glomerular filtration rate. Radiology. 2014; 271: 65-73. doi: 10.1148/ radiol.13130775.

73. McDonald RJ, McDonald JS, Bida JP, Carter RE, Fleming CJ, Misra S, Williamson EE, Kallmes DF. Intravenous contrast material-induced nephropathy: causal or coincident phenomenon? Radiology. 2013; 267: 106-18. doi: 10.1148/ radiol.12121823.

74. Moos SI, van Vemde DN, Stoker J, Bipat S. Contrast induced nephropathy in patients undergoing intravenous (IV) contrast enhanced computed tomography (CECT) and the relationship with risk factors: a meta-analysis. Eur J Radiol. 2013; 82: e387-99. doi: 10.1016/j. ejrad.2013.04.029.

75. Launay-Vacher V. Epidemiology of chronic kidney disease in cancer patients: lessons from the IRMA study group. Semin Nephrol. 2010; 30: 548-56. doi: 10.1016/j. semnephrol.2010.09.003.

76. Dogan E, Izmirli M, Ceylan K, Erkoc R, Sayarlioglu H, Begenik H, Alici S. Incidence of renal insufficiency in cancer patients. Adv Ther. 2005; 22: 357-62.

77. Launay-Vacher V, Izzedine H, Rey JB, Rixe O, Chapalain S, Nourdine S, Paci A, Bourget P, Deray G. Incidence of renal insufficiency in cancer patients and evaluation of information available on the use of anticancer drugs in renally impaired patients. Med Sci Monit. 2004; 10: CR209-12.

78. Launay-Vacher V, Oudard S, Janus N, Gligorov J, Pourrat X, Rixe O, Morere JF, Beuzeboc P, Deray G; Renal Insufficiency and Cancer Medications (IRMA) Study Group. Prevalence of Renal Insufficiency in cancer patients and implications for anticancer drug management: the renal insufficiency and anticancer medications (IRMA) study. Cancer. 2007; 110: 1376-84. doi: 10.1002/cncr.22904.

79. Janus N, Oudard S, Beuzeboc P, Gligorov J, Ray-Coquard I, Morere J, Spano J, Pourrat X, Deray G, Launay-Vacher V. Prevalence of renal insufficiency in cancer patients: data from the IRMA-2 study. J Clin Oncol. 2009; 27: 9559. doi:10.1200/jco.2009.27.15_suppl.9559.

80. Levey AS, de Jong PE, Coresh J, El Nahas M, Astor BC, Matsushita K, Gansevoort RT, Kasiske BL, Eckardt KU. The definition, classification, and prognosis of chronic kidney disease: a KDIGO Controversies Conference report. Kidney Int. 2011; 80: 17-28. doi: 10.1038/ki.2010.483.

81. Huang WC, Levey AS, Serio AM, Snyder M, Vickers AJ, Raj GV, Scardino PT, Russo P. Chronic kidney disease after nephrectomy in patients with renal cortical tumours: a retrospective cohort study. Lancet Oncol. 2006; 7: 735-40. doi: 10.1016/S1470-2045(06)70803-8.

82. Janus N, Launay-Vacher V, Byloos E, Machiels JP, Duck L, Kerger J, Wynendaele W, Canon JL, Lybaert W, Nortier J, Deray G, Wildiers H. Cancer and renal insufficiency results of the BIRMA study. Br J Cancer. 2010; 103: 1815-21. doi: 10.1038/sj.bjc.6605979.

83. Canter D, Kutikov A, Sirohi M, Street R, Viterbo R, Chen DY, Greenberg RE, Uzzo RG. Prevalence of baseline chronic kidney disease in patients presenting with solid renal tumors. Urology. 2011; 77: 781-5. doi: 10.1016/j. urology.2010.11.050.

84. Nakamura Y, Tsuchiya K, Nitta K, Ando M. Prevalence of anemia and chronic kidney disease in cancer patients: clinical significance for 1-year mortality. Nihon Jinzo Gakkai Shi. 2011; 53: 38-45.

85. Launay-Vacher V, Gligorov J, Le Tourneau C, Janus N, Spano JP, Ray-Coquard I, Oudard S, Pourrat X, Morere JF, Deray G, Beuzeboc P; Renal Insufficiency and Anticancer Medications (IRMA) Study Group.. Prevalence of renal insufficiency in breast cancer patients and related pharmacological issues. Breast Cancer Res Treat. 2010; 124: 745-53. doi: 10.1007/s10549-008-0131-1.

86. Launay-Vacher V, Etessami R, Janus N, Spano JP, RayCoquard I, Oudard S, Gligorov J, Pourrat X, Beuzeboc P, Deray G, Morere JF; Renal Insufficiency Anticancer Medications (IRMA) Study Group. Lung cancer and renal insufficiency: prevalence and anticancer drug issues. Lung. 2009; 187: 69-74. doi: 10.1007/s00408-008-9123-5.

87. Launay-Vacher V, Ayllon J, Janus N, Spano JP, RayCoquard I, Gligorov J, Pourrat X, Morere JF, Beuzeboc P, Deray G, Oudard S; Renal Insufficiency and Anticancer Medications (IRMA) Study Group. Drug management 
of prostate cancer: prevalence and consequences of renal insufficiency. Clin Genitourin Cancer. 2009; 7: E83-9. doi: 10.3816/CGC.2009.n.029.

88. Yang Y, Li H, Zhou Q, Peng Z, An X, Li W, Xiong L, Yu $\mathrm{X}$, Jiang W, Mao H. Renal function and all-cause mortality risk among cancer patients. Medicine (Baltimore). 2016; 95. doi: 10.1097/md.0000000000003728.

89. Wong G, Hayen A, Chapman JR, Webster AC, Wang JJ, Mitchell P, Craig JC. Association of CKD and cancer risk in older people. J Am Soc Nephrol. 2009; 20: 1341-50. doi: 10.1681/ASN.2008090998.

90. Orskov B, Sorensen VR, Feldt-Rasmussen B, Strandgaard $\mathrm{S}$. Changes in causes of death and risk of cancer in Danish patients with autosomal dominant polycystic kidney disease and end-stage renal disease. Nephrol Dial Transplant. 2012; 27: 1607-13. doi: 10.1093/ndt/gfr467.

91. Lowrance WT, Ordonez J, Udaltsova N, Russo P, Go AS. CKD and the risk of incident cancer. J Am Soc Nephrol. 2014; 25: 2327-34. doi: 10.1681/ASN.2013060604.

92. Maisonneuve P, Agodoa L, Gellert R, Stewart JH, Buccianti G, Lowenfels AB, Wolfe RA, Jones E, Disney AP, Briggs $\mathrm{D}$, McCredie M, Boyle P. Cancer in patients on dialysis for end-stage renal disease: an international collaborative study. Lancet. 1999; 354: 93-9.

93. Engels EA, Pfeiffer RM, Fraumeni JF Jr, Kasiske BL, Israni AK, Snyder JJ, Wolfe RA, Goodrich NP, Bayakly AR, Clarke CA, Copeland G, Finch JL, Fleissner ML, et al. Spectrum of cancer risk among US solid organ transplant recipients. JAMA. 2011; 306: 1891-901. doi: 10.1001/ jama.2011.1592.

94. US Renal Data System, USRDS 2003 Annual Data Report: Atlas of end-stage renal disease in the United States. Bethesda, MD, National Institutes of Health, National Institute of Diabetes and Digestive and Kidney Diseases, 2003.

95. Butler AM, Olshan AF, Kshirsagar AV, Edwards JK, Nielsen ME, Wheeler SB, Brookhart MA. Cancer incidence among US Medicare ESRD patients receiving hemodialysis, 19962009. Am J Kidney Dis. 2015; 65: 763-72. doi: 10.1053/j. ajkd.2014.12.013.

96. Hall EC, Pfeiffer RM, Segev DL, Engels EA. Cumulative incidence of cancer after solid organ transplantation. Cancer. 2013; 119: 2300-8. doi: 10.1002/cncr.28043.

97. Lin HF, Li YH, Wang CH, Chou CL, Kuo DJ, Fang TC. Increased risk of cancer in chronic dialysis patients: a population-based cohort study in Taiwan. Nephrol Dial Transplant. 2012; 27: 1585-90. doi: 10.1093/ndt/gfr464.

98. Bechade C, Dejardin O, Bara S, Bouvier V, Guizard AV, De Mil R, Troussard X, Lobbedez T, Launoy G. Incidence and characteristics of chronic renal replacement therapy in patients with cancer: data from kidney and cancer registries in Basse-Normandie. J Nephrol. 2016. doi: 10.1007/ s40620-016-0356-8.

99. Vajdic CM, McDonald SP, McCredie MR, van Leeuwen MT, Stewart JH, Law M, Chapman JR, Webster AC, Kaldor
JM, Grulich AE. Cancer incidence before and after kidney transplantation. JAMA. 2006; 296: 2823-31. doi: 10.1001/ jama.296.23.2823.

100. Stengel B. Chronic kidney disease and cancer: a troubling connection. J Nephrol. 2010; 23: 253-62.

101. Avissar N, Ornt DB, Yagil Y, Horowitz S, Watkins RH, Kerl EA, Takahashi K, Palmer IS, Cohen HJ. Human kidney proximal tubules are the main source of plasma glutathione peroxidase. Am J Physiol. 1994; 266: C367-75.

102. Descamps-Latscha B. The immune system in end-stage renal disease. Curr Opin Nephrol Hypertens. 1993; 2: 883-91.

103. Kato S, Chmielewski M, Honda H, Pecoits-Filho R, Matsuo S, Yuzawa Y, Tranaeus A, Stenvinkel P, Lindholm B. Aspects of immune dysfunction in end-stage renal disease. Clin J Am Soc Nephrol. 2008; 3: 1526-33. doi: 10.2215/ CJN.00950208.

104. Bonomini M, Forster S, De Risio F, Rychly J, Nebe B, Manfrini V, Klinkmann H, Albertazzi A. Effects of selenium supplementation on immune parameters in chronic uraemic patients on haemodialysis. Nephrol Dial Transplant. 1995; 10: 1654-61.

105. Gonzalez EA, Sachdeva A, Oliver DA, Martin KJ. Vitamin D insufficiency and deficiency in chronic kidney disease. A single center observational study. Am J Nephrol. 2004; 24 : 503-10. doi: 10.1159/000081023.

106. Yoshimura S, Suemizu H, Nomoto Y, Sakai H, Katsuoka Y, Kawamura N, Moriuchi T. Plasma glutathione peroxidase deficiency caused by renal dysfunction. Nephron. 1996; 73 : 207-11.

107. Connelly-Frost A, Poole C, Satia JA, Kupper LL, Millikan RC, Sandler RS. Selenium, folate, and colon cancer. Nutr Cancer. 2009; 61: 165-78. doi: 10.1080/01635580802404188.

108. Lange JH. Reanalysis of epidemiological data for selenium anti-cancer activity. Toxicol Ind Health. 1991; 7: 319-25.

109. Wu K, Feskanich D, Fuchs CS, Willett WC, Hollis BW, Giovannucci EL. A nested case control study of plasma 25-hydroxyvitamin D concentrations and risk of colorectal cancer. J Natl Cancer Inst. 2007; 99: 1120-9. doi: 10.1093/ jnci/djm038.

110. Oster HS, Neumann D, Hoffman M, Mittelman M. Erythropoietin: the swinging pendulum. Leuk Res. 2012; 36: 939-44. doi: 10.1016/j.leukres.2012.04.017.

111. Szenajch J, Wcislo G, Jeong JY, Szczylik C, Feldman L. The role of erythropoietin and its receptor in growth, survival and therapeutic response of human tumor cells From clinic to bench - a critical review. Biochim Biophys Acta. 2010; 1806: 82-95. doi: 10.1016/j.bbcan.2010.04.002.

112. Holley JL. Screening, diagnosis, and treatment of cancer in long-term dialysis patients. Clin J Am Soc Nephrol. 2007; 2: 604-10. doi: 10.2215/CJN.03931106.

113. Oneschuk D, Fainsinger R. Medical and ethical dilemmas when an advanced cancer patient discontinues dialysis. J Palliat Care. 2002; 18: 123-6. 
114. Wenger NS, Lynn J, Oye RK, Liu H, Teno JM, Phillips RS, Desbiens NA, Sehgal A, Kussin P, Taub H, Harrell F, Knaus W. Withholding versus withdrawing life-sustaining treatment: patient factors and documentation associated with dialysis decisions. J Am Geriatr Soc. 2000; 48: S75-83.

115. Poppel DM, Cohen LM, Germain MJ. The renal palliative care initiative. J Palliat Med. 2003; 6: 321-6. doi: 10.1089/109662103764978650.

116. Birmele B, Francois M, Pengloan J, Francais P, Testou D, Brillet G, Lechapois D, Baudin S, Grezard O, Jourdan JL, Fodil-Cherif M, Abaza M, Dupouet L, et al. Death after withdrawal from dialysis: the most common cause of death in a French dialysis population. Nephrol Dial Transplant. 2004; 19: 686-91.

117. Scherer JS, Swidler MA. Decision-making in patients with cancer and kidney disease. Adv Chronic Kidney Dis. 2014; 21: 72-80. doi: 10.1053/j.ackd.2013.07.005.

118. Hayakawa K, Matsumoto M, Aoyagi T, Miyaji K, Hata M. Prostate cancer with multiple lung metastases in a hemodialysis patient. Int J Urol. 2000; 7: 464-6.

119. Krediet RT. Dialysate cancer antigen 125 concentration as marker of peritoneal membrane status in patients treated with chronic peritoneal dialysis. Perit Dial Int. 2001; 21: 560-7.

120. Wolff JM, Ting O, Borchers H, Rohde D, Jakse G. Serum levels of prostate specific antigen in men on hemodialysis. Anticancer Res. 2000; 20: 5191-3.

121. Rule AD, Bergstralh EJ, Slezak JM, Bergert J, Larson TS. Glomerular filtration rate estimated by cystatin C among different clinical presentations. Kidney Int. 2006; 69: 399405. doi: 10.1038/sj.ki.5000073.

122. Bellomo R, Kellum JA, Ronco C. Defining acute renal failure: physiological principles. Intensive Care Med. 2004; 30: 33-7. doi: 10.1007/s00134-003-2078-3.

123. Rahn KH, Heidenreich S, Bruckner D. How to assess glomerular function and damage in humans. J Hypertens. 1999; 17: 309-17.

124. Coresh J, Astor BC, Greene T, Eknoyan G, Levey AS. Prevalence of chronic kidney disease and decreased kidney function in the adult US population: Third National Health and Nutrition Examination Survey. Am J Kidney Dis. 2003; 41: 1-12. doi: 10.1053/ajkd.2003.50007.

125. Levey AS, Stevens LA, Schmid CH, Zhang YL, Castro AF 3rd, Feldman HI, Kusek JW, Eggers P, Van Lente F, Greene T, Coresh J; CKD-EPI. A new equation to estimate glomerular filtration rate. Ann Intern Med. 2009; 150: 604-12.

126. Collins AJ, Li S, Gilbertson DT, Liu J, Chen SC, Herzog CA. Chronic kidney disease and cardiovascular disease in the Medicare population. Kidney Int Suppl. 2003; 87: S24-31.

127. Fliser D, Franek E, Joest M, Block S, Mutschler E, Ritz E. Renal function in the elderly: impact of hypertension and cardiac function. Kidney Int. 1997; 51: 1196-204.
128. Feinfeld DA, Keller S, Somer B, Wassertheil-Smoller S, Carvounis CP, Aronson M, Nelson M, Frishman WH. Serum creatinine and blood urea nitrogen over a six-year period in the very old. Creatinine and BUN in the very old. Geriatr Nephrol Urol. 1998; 8: 131-5.

129. Bachorzewska-Gajewska H, Malyszko J, Malyszko JS, Dobrzycki S, Sobkowicz B, Musial W. Estimation of glomerular filtration rate in patients with normal serum creatinine undergoing primary PCI: is it really normal? Nephrol Dial Transplant. 2006; 21: 1736-8. doi: 10.1093/ ndt/gfi324.

130. Food and Drug Administration. Guidance for industry: Pharmacokinetics in patients with impaired renal function - Study design, data analysis, and impact on dosing and labeling. US Department of Health and Human Services, Rockville, MD 1998. http:/www.fda.gov/downloads/Drugs/ GuidanceComplianceRegulatoryInformation/Guidances/ ucm072127.pdf

131. Iff S, Craig JC, Turner R, Chapman JR, Wang JJ, Mitchell P, Wong G. Reduced estimated GFR and cancer mortality. Am J Kidney Dis. 2014; 63: 23-30. doi: 10.1053/j. ajkd.2013.07.008.

132. Na SY, Sung JY, Chang JH, Kim S, Lee HH, Park YH, Chung W, Oh KH, Jung JY. Chronic kidney disease in cancer patients: an independent predictor of cancerspecific mortality. Am J Nephrol. 2011; 33: 121-30. doi: 10.1159/000323740.

133. Matsumoto S, Takayama T, Wakatsuki K, Tanaka T, Migita K, Nakajima Y. Short-term and long-term outcomes after gastrectomy for gastric cancer in patients with chronic kidney disease. World J Surg. 2014; 38: 1453-60. doi: 10.1007/s00268-013-2436-4.

134. Nozawa H, Kitayama J, Sunami E, Watanabe T. Impact of chronic kidney disease on outcomes of surgical resection for primary colorectal cancer: a retrospective cohort review. Dis Colon Rectum. 2012; 55: 948-56. doi: 10.1097/ DCR.0b013e3182600db7.

135. Dubose AC, Chu QD, Li BD, Kim RH. Is chronic kidney disease an independent risk factor for mortality in breast cancer? J Surg Res. 2013; 184: 260-4. doi: 10.1016/j. jss.2013.04.035.

136. Konigsbrugge O, Lotsch F, Zielinski C, Pabinger I, Ay C. Chronic kidney disease in patients with cancer and its association with occurrence of venous thromboembolism and mortality. Thromb Res. 2014; 134: 44-9. doi: 10.1016/j. thromres.2014.04.002.

137. Currie A, Malietzis G, Askari A, Nachiappan S, Swift P, Jenkins JT, Faiz OD, Kennedy RH. Impact of chronic kidney disease on postoperative outcome following colorectal cancer surgery. Colorectal Dis. 2014; 16: 87985. doi: 10.1111/codi.12665.

138. Lichtman SM, Cirrincione CT, Hurria A, Jatoi A, Theodoulou M, Wolff AC, Gralow J, Morganstern DE, Magrinat G, Cohen HJ, Muss HB. Effect of pretreatment 
renal function on treatment and clinical outcomes in the adjuvant treatment of older women with breast cancer: Alliance A171201, an Ancillary Study of CALGB/CTSU 49907. J Clin Oncol. 2016; 34: 699-705. doi: 10.1200/ jco.2015.62.6341.

139. Hsiao LT, Yang CF, Yang SH, Gau JP, Yu YB, Hong YC, Liu CY, Liu JH, Chen PM, Chiou TJ, Tzeng $\mathrm{CH}$. Chronic kidney disease stage 5 as the prognostic complement of International Staging System for multiple myeloma. Eur J Haematol. 2012; 88: 159-66. doi: 10.1111/j.1600-0609.2011.01717.x.

140. Lichtman SM, Wildiers H, Launay-Vacher V, Steer C, Chatelut E, Aapro M. International Society of Geriatric Oncology (SIOG) recommendations for the adjustment of dosing in elderly cancer patients with renal insufficiency. Eur J Cancer. 2007; 43: 14-34. doi: 10.1016/j. ejca.2006.11.004.

141. Nikolsky E, Mehran R, Lasic Z, Mintz GS, Lansky AJ, Na Y, Pocock S, Negoita M, Moussa I, Stone GW, Moses JW, Leon MB, Dangas G. Low hematocrit predicts contrast-induced nephropathy after percutaneous coronary interventions. Kidney Int. 2005; 67: 706-13. doi: 10.1111/j.1523-1755.2005.67131.x.

142. Janus N, Launay-Vacher V, Thyss A, Boulanger H, Moranne O, Islam MS, Durande JP, Ducret M, Juillard L, Soltani Z, Motte G, Rottembourg J, Deray G, et al. Management of anticancer treatment in patients under chronic dialysis: results of the multicentric CANDY (CANcer and DialYsis) study. Ann Oncol. 2013; 24: 501-7. doi: 10.1093/annonc/ mds344.

143. Boesler B, Czock D, Keller F, Griesshammer M, Seufferlein T, Karges W, Rasche FM. Clinical course of haemodialysis patients with malignancies and dose-adjusted chemotherapy. Nephrol Dial Transplant. 2005; 20: 1187-91. doi: 10.1093/ ndt/gfh807.

144. Dettli L. Drug dosage in renal disease. Clin Pharmacokinet. 1976; 1: 126-34.

145. Suthanthiran M, Strom TB. Renal transplantation. $\mathrm{N}$ Engl J Med. 1994; 331: 365-76. doi: 10.1056/ NEJM199408113310606.

146. Wolfe RA, Ashby VB, Milford EL, Ojo AO, Ettenger RE, Agodoa LY, Held PJ, Port FK. Comparison of mortality in all patients on dialysis, patients on dialysis awaiting transplantation, and recipients of a first cadaveric transplant. $\mathrm{N}$ Engl J Med. 1999; 341: 1725-30. doi: 10.1056/ NEJM199912023412303.

147. Malyszko J, Dryl-Rydzynska T, Marcinkowski W, Prystacki T, Malyszko JS. Comorbidities on kidney transplantation waiting list relative to the status of the potential recipient. Arch Med Sci. 2016. doi: 10.5114/aoms.2016.60337.

148. Maisonneuve P, Agodoa L, Gellert R, Stewart JH, Buccianti G, Lowenfels AB, Wolfe RA, Jones E, Disney AP, Briggs $\mathrm{D}$, McCredie M, Boyle P. Cancer in patients on dialysis for end-stage renal disease: an international collaborative study. Lancet. 1999; 354: 93-9.

149. Mosconi G, Centofanti F, Capelli I, Ricci A, Persici E, Gandolfini I, Rubbiani E, Buzio C, Cappelli G, Costa AN, Stefoni S. Incidence and prevalence of cancer in kidney transplantation waiting list patients: an Italian experience. Int J Artif Organs. 2013; 36: 335-40. doi: 10.5301/ ijao.5000203.

150. Kasiske BL, Cangro CB, Hariharan S, Hricik DE, Kerman RH, Roth D, Rush DN, Vazquez MA, Weir MR; American Society of Transplantation. The evaluation of renal transplantation candidates: clinical practice guidelines. Am J Transplant. 2001; 1: 3-95.

151. Knoll G, Cockfield S, Blydt-Hansen T, Baran D, Kiberd B, Landsberg D, Rush D, Cole E; Kidney Transplant Working Group of the Canadian Society of Transplantation. Canadian Society of Transplantation consensus guidelines on eligibility for kidney transplantation. CMAJ. 2005; 173: 1181-4. doi: 10.1503/cmaj.051291.

152. Kasiske BL, Ramos EL, Gaston RS, Bia MJ, Danovitch GM, Bowen PA, Lundin PA, Murphy KJ. The evaluation of renal transplant candidates: clinical practice guidelines. Patient Care and Education Committee of the American Society of Transplant Physicians. J Am Soc Nephrol. 1995; 6: 1-34.

153. Abbud-Filho M, Adams PL, Alberu J, Cardella C, Chapman J, Cochat P, Cosio F, Danovitch G, Davis C, Gaston RS, Humar A, Hunsicker LG, Josephson MA, et al. A report of the Lisbon Conference on the care of the kidney transplant recipient. Transplantation. 2007; 83: S1-22. doi: 10.1097/01.tp.0000260765.41275.e2.

154. Abramowicz D, Cochat P, Claas FH, Heemann U, Pascual J, Dudley C, Harden P, Hourmant M, Maggiore U, Salvadori M, Spasovski G, Squifflet JP, Steiger J, et al. European Renal Best Practice Guideline on kidney donor and recipient evaluation and perioperative care. Nephrol Dial Transplant. 2015; 30: 1790-7. doi: 10.1093/ndt/gfu216.

155. Batabyal P, Chapman JR, Wong G, Craig JC, Tong A. Clinical practice guidelines on wait-listing for kidney transplantation: consistent and equitable? Transplantation. 2012; 94: 703-13. doi: 10.1097/TP.0b013e3182637078.

156. Bunnapradist S, Danovitch GM. Evaluation of adult kidney transplant candidates. Am J Kidney Dis. 2007; 50: 890-8. doi: 10.1053/j.ajkd.2007.08.010.

157. Chapman JR, Sheil AG, Disney AP. Recurrence of cancer after renal transplantation. Transplant Proc. 2001; 33: 1830-1.

158. Barrett WL, First MR, Aron BS, Penn I. Clinical course of malignancies in renal transplant recipients. Cancer. 1993; 72: 2186-9.

159. Penn I. The effect of immunosuppression on pre-existing cancers. Transplantation. 1993; 55: 742-7.

160. Trofe J, Buell JF, Woodle ES, Beebe TM, Hanaway MJ, First MR, Alloway RR, Gross TG. Recurrence risk after 
organ transplantation in patients with a history of Hodgkin disease or non-Hodgkin lymphoma. Transplantation. 2004; 78: 972-7.

161. Engels EA, Pfeiffer RM, Fraumeni JF Jr, Kasiske BL, Israni AK, Snyder JJ, Wolfe RA, Goodrich NP, Bayakly AR, Clarke CA, Copeland G, Finch JL, Fleissner ML, et al. Spectrum of cancer risk among US solid organ transplant recipients. JAMA. 2011; 306: 1891-901. doi: 10.1001/ jama.2011.1592.

162. Farrugia D, Mahboob S, Cheshire J, Begaj I, Khosla S, Ray D, Sharif A. Malignancy-related mortality following kidney transplantation is common. Kidney Int. 2014; 85: 1395-403. doi: 10.1038/ki.2013.458.

163. Kiberd BA, Rose C, Gill JS. Cancer mortality in kidney transplantation. Am J Transplant. 2009; 9: 1868-75. doi: 10.1111/j.1600-6143.2009.02728.x.

164. Acuna SA, Fernandes KA, Daly C, Hicks LK, Sutradhar R, Kim SJ, Baxter NN. Cancer mortality among recipients of solid-organ transplantation in Ontario, Canada. JAMA Oncol. 2016; 2: 463-9. doi: 10.1001/jamaoncol.2015.5137.

165. Acuna SA, Huang JW, Daly C, Shah PS, Kim SJ, Baxter NN. Outcomes of solid organ transplant recipients with preexisting malignancies in remission: a systematic review and meta-analysis. Transplantation. 2017; 101: 471-81. doi: 10.1097/TP.0000000000001192.

166. Acuna SA, Huang JW, Scott AL, Micic S, Daly C, Brezden-Masley C, Kim SJ, Baxter NN. Cancer screening recommendations for solid organ transplant recipients: a systematic review of clinical practice guidelines. Am J Transplant. 2017; 17: 103-14. doi: 10.1111/ajt.13978.

167. Wanchoo R, Riella LV, Uppal NN, Lopez CA, Nair V, Devoe C, Jhaveri KD. Immune checkpoint inhibitors in the cancer patient with an organ transplant. J Onconephrol. 2017; 1: 42-8. doi: 10.5301/jo-n.5000006.

168. Yanik EL, Gustafson SK, Kasiske BL, Israni AK, Snyder JJ, Hess GP, Engels EA, Segev DL. Sirolimus use and cancer incidence among US kidney transplant recipients. Am J Transplant. 2015; 15: 129-36. doi: 10.1111/ajt.12969.

169. Abujudeh HH, Gee MS, Kaewlai R. In emergency situations, should serum creatinine be checked in all patients before performing second contrast CT examinations within 24 hours? J Am Coll Radiol. 2009; 6: 268-73. doi: 10.1016/j.jacr.2008.09.014. 